\title{
Improving the UX for Users of Automated Shuttle Buses in Public Transport: Investigating Aspects of Exterior Communication and Interior Design
}

\author{
Andreas Riener ${ }^{1, *,+} \mathbb{D}$, Dominik Schlack1 $2,+\mathbb{D}$, Julia Malsam ${ }^{2,+}$, Josef Huber $2,+$, Benjamin Homm $2,+, \ddagger$,

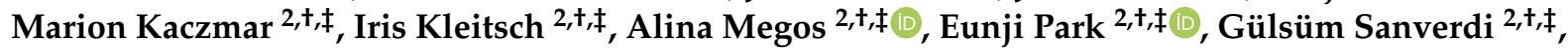 \\ Sabrina Schmidt $2,+, \neq$, Daniel Bracaci ${ }^{2,+}$ and Esha Anees ${ }^{2,+} \mathbb{D}$
}

check for

updates

Citation: Riener, A.; Schlackl, D.;

Malsam, J.; Huber, J.; Homm, B.;

Kaczmar, M.; Kleitsch, I.; Megos, A.;

Park, E.; Sanverdi, G.; et al.

Improving the UX for Users of

Automated Shuttle Buses in Public

Transport: Investigating Aspects of

Exterior Communication and Interior Design. Multimodal Technol. Interact. 2021, 5, 61. https://doi.org/10.3390/ mti5100061

Academic Editors: Shadan Sadeghian Borojeni, Philipp Wintersberger and Derek L. Hansen

Received: 21 March 2021

Accepted: 25 September 2021

Published: 9 October 2021

Publisher's Note: MDPI stays neutral with regard to jurisdictional claims in published maps and institutional affiliations.

Copyright: (c) 2021 by the authors Licensee MDPI, Basel, Switzerland This article is an open access article distributed under the terms and conditions of the Creative Commons Attribution (CC BY) license (https:// creativecommons.org/licenses/by/ $4.0 /)$.
1 Technische Hochschule Ingolstadt (THI), Human-Computer Interaction Group, 85409 Ingolstadt, Germany

2 Technische Hochschule Ingolstadt (THI), 85409 Ingolstadt, Germany; dos4091@thi.de (D.S.); jum5134@thi.de (J.M.); joh7739@thi.de (J.H.); beh5360@thi.de (B.H.); mak3888@thi.de (M.K.); irk7827@thi.de (I.K.); alm0615@thi.de (A.M.); eup7017@thi.de (E.P.); gus9066@thi.de (G.S.); sas2393@thi.de (S.S.); dab8159@thi.de (D.B.); esa4930@thi.de (E.A.)

* Correspondence: andreas.riener@thi.de; Tel.: +49-841-9348-2833

$\dagger$ We applied the SDC approach for the sequence of authors.

$\ddagger$ These authors contributed equally to this work.

Abstract: As a precursor to future public transportation, automated shuttle buses can already be experienced in some test regions, but the general public still has reservations and may not yet be ready for this change. For example, the fact that such vehicles might operate independently (without a human driver) creates a barrier of uncertainty and mistrust among people. In this work, we aim to identify and classify the prevailing reservations and propose solutions. We followed the User Centered Design (UCD) process to design concepts that are specifically tailored to the needs of future public transport users. After related work analysis, on-site research, and pre-studies, two main studies were conducted specifically to address communication in the exterior $(n=24)$ and interior/service design $(n=21)$. For both studies, we applied a mixed-methods approach combining quantitative and qualitative measures. Our results indicate that, in general, existing ways of communication in the exterior are insufficient to meet future needs. The two visualization concepts for external communication developed in this work were rated (significantly) better in most dimensions of the User Experience Questionnaire (UEQ), when compared to the baseline condition with no additional visualization. Furthermore, preferences among the study participants towards simple, highly visible, and well-known lighting concepts could be observed. As for the interior, the results show that participants rated attractiveness highly for the two design concepts (closer, further in the future) as compared to current, state-of-the-art solutions (automated buses currently in operation). For the "near future" concept, the pragmatic quality dominated, while in the other (the "far future") concept the hedonic quality was in the foreground. From the results, design recommendations in different categories were derived, which reflect the general openness of the public towards new technologies and interior approaches, but also point out the importance for privacy and designated personal spaces inside an (automated) shuttle bus. Some of the results do not strictly apply to automated shuttle buses, and can serve as valuable suggestions for improving conventional shuttle buses.

Keywords: automated shuttle buses; public transport; user experience; user centered design; exterior communication; interior design; future mobility services

\section{Introduction}

As the mobility sector is changing, advancing technological developments over the last decade have progressively enabled the deployment of autonomous vehicles (AVs) in public road traffic [1]. Following this trend, public transport operators have 
defined the widespread application of autonomous shuttle buses as a supplement to public transport as an important corporate strategy, e.g., [2] (Chapter 1.2), and initiated test projects. Examples are the "SmartShuttle" project in Sion, Switzerland (https: / / www.postauto.ch/en/project-smartshuttle, accessed on 29 July 2021), the "auto.BusSeestadt" project in Vienna, Austria (https:/ / www.ait.ac.at/en/research-topics/integratedmobility-systems/ projects / autobus-seestadt, accessed on 29 July 2021), or the "Bad Birnbach Shuttle" (line 7015) in Bad Birnbach, Bavaria [2]. Braun et al. [3] provide an overview of about 40 current projects in Germany.

In order to be able to better estimate the expected scope of functions and system complexity, it is important to provide a clear definition of terms. The public typically talks about "autonomous driving" without questioning it further. As the shuttle buses under investigation in this work operate on pre-programmed routes, they are not acting autonomously according to the definition of the term [4]. In the course of this article, we thus refer to this technology as automated shuttle buses.

Related research has also proven that automated shuttle buses will become an important supplement to public transport, since they provide an innovative, sustainable, profitable, and demand-oriented mode of transport that can in particular provide a remedy for off-season times and the first and last mile operation in suburban areas that could not otherwise be served economically [5]. In recent years, automated (and autonomous) driving was controversially debated, e.g., [6,7]. It is also a matter of fact that the future development of this technology will be increasingly dependent on public acceptance, trust in the technology, and the consideration of personal needs and expectations [8]. At this early stage of development and public launch, riding in a shuttle bus without an operator on public roads, in downtown areas or pedestrian zones, creates anxiety among the public [9].

This situation currently represents a general usage barrier for the broader society. The motivation of this work was to make the use of automated shuttle buses more attractive for the passenger and thus to ensure pleasant future mobility as a precondition for selfdetermination and an individual lifestyle. In this context, the questions to address are, among others, how this barrier can be reduced and what main concerns need to be solved in order to achieve a better user experience (UX) of automated shuttle buses.

This article presents the findings of research aimed at identifying and developing potential solutions that are tailored to the specific needs of public transport users for both exterior and interior categories of automated shuttle buses.

\section{Outline}

The rest of the article is structured as follows. Section 2 presents related concepts and discusses findings about existing solutions and current state-of-the-art research, separate for exterior and interior categories of automated shuttle buses. Section 3 introduces the overall methodology and research approach applied to this work. Study designs and procedures for the reported studies are described in the Section 4 (on-site research), Section 5 (prestudies), and Section 6 (main studies). Quantitative and qualitative results of the main studies are presented in Section 7 and subsequently discussed in Section 8. Section 9 concludes the article, including limitations and recommendations for future work.

\section{Related Work}

Related work is discussed below and the current state of research is reviewed to identify research gaps from which the further direction of this project was derived. For the literature search, Google Scholar and databases (ACM Digital Library, IEEE Xplore, Science Direct) were utilized. A two-step search approach was used (more general keywords for exterior/interior of automated shuttle buses in the first step, then refinement by more specific terms and backward search).

Recently, numerous research works addressing the problems of automated vehicles in road traffic, e.g., policy and society implications [10], public opinion [11], architectural perspectives [12], motion control [13], communication needs [14], uncertainty and anticipa- 
tion in traffic [15], and interior design [16] were published. More specifically, aspects of automated shuttle buses operating in public traffic, such as general state-of-the-art [17], routing [18], pickup and delivery [19], time tables/scheduling [20], last-mile problem [21], safety/security [22], economy, fare and subsidy [23], external communication/eHMIs [24-26], seating position [18,27], etc. were also addressed. In this work, we drew on these general and specific findings, identified research gaps separately for the exterior and interior categories, and addressed them through additional research (Sections 4-6).

\subsection{Exterior of the Automated Shuttle Bus}

After initial related work analysis, the use of clustering facilitated the identification of four major research areas (each with a wide range of problems) related to the exterior category of an automated shuttle bus:

- Communication and Interaction: Considers how other road users communicate and interact effectively with automated vehicles.

- Safety and Trust: Includes which aspects influence perceived safety, trust, and user experience.

- Accessibility: Pertains to services providing sufficient space and assistive features for persons with specific needs.

- Availability: Considers flexible mobility networks such as Mobility on Demand (MoD).

The first area, communication and interaction, is by far the most discussed in the literature. For the current project, this area also provides the most opportunities for the development and evaluation of new concepts. For this reason, the project team has decided to pursue only this area and to continue with a detailed analysis of related work. The results are presented in the following section.

A number of comprehensive reviews, e.g., [24,26], and papers/articles [28-33] on general aspects for external communication between automated vehicles and other road participants (eHMIs) were published over the last years. Löcken et al. [34] add that people want to be able to anticipate the vehicles actions and expect an AV to behave similar to a manually driven car. They further indicate that pedestrians are not sure if the AV recognized them and is going to stop. Moreover, it is unclear to pedestrians when they are in the security zone around the bus (and the AV stops for this reason). In the following section, several studies and approaches addressing these communication and interaction problems will be introduced and discussed in the light of this project.

\subsubsection{Aspect \#1 Communication Using Visual Signals}

As Ackermann et al. [35] suggested, visual intent indicators could be grouped by technical implementation: projections located at the windscreen or street surface, LED light stripes or displays on the radiator grille and windscreen. Clamann et al. [36] reveal that visual signals on cars have no significant effect on crossing decisions. In contrast, several studies [37-39] found that visual displays are useful and increase the perception of safety. Overall, the effectiveness of visual intent indicators is unclear. Nevertheless, explicit communication could be helpful in supporting interaction between AVs and road users. Through visual signals, AVs tell road users what to do next (e.g., stop and wait at a crosswalk) and provide important information. The visual signal concept can also be used to warn pedestrians or cyclists of dangerous situations [40]. Löcken et al. [34] found that most people prefer communication via simple light signals. Moreover, by changing the speed and direction of the light signal, the LED display can indicate whether autonomous cars are accelerating or braking [40]. Dey and colleagues [25] also analyzed animation patterns and concluded that a uniformly flashing or pulsing animation is preferred compared to any pattern that animates sideways. As a side note, Amini et al. [24] suggest that eHMI concepts for nonverbal communication could also use speaker systems to transmit audible messages. 


\subsubsection{Aspect \#2 Color Signals Indicating the Current Driving Status}

It is often mentioned that people prefer simple communication systems familiar to established concepts, such as concepts inspired by traffic light signals (green and red) [39,41,42]. Wintersberger et al. [41] and Löcken et al. [39] also indicated that there is a clear preference for unambiguous and standardized solutions. Moreover, Holländer et al. [37] designed a visual communication concept based on traffic lights. They [37] found out, that it reduced pedestrian decision time significantly and it scored highest in understandability and personal preference because of its familiarity. Mercedes Benz [43] applies green and red lights which give signals to the passengers for boarding or departure when the door opens and closes at the bus stop. Audi [40] also indicates a green light signal on its front display to pedestrians when it is safe to cross in front of the car. In contrast, by using a red light signal, the car gives them a warning not to cross. In addition to traffic light colors, Dey et al. [25] found that cyan was well suited as a neutral color for communicating a yielding intention.

\subsubsection{Aspect \#3 Communication Using Human-Like Behavior}

Chang et al. [44] designed a visual interface adding eyes on a car. This interface is able to express the car's intention by establishing eye contact with pedestrians and it can therefore help pedestrians to make a correct street-crossing decision, as it can increase the subjective feeling of safety. Moreover, Hutson [45] describes that a humanized car makes the passengers feel calm in emergencies by giving the car a voice and verbalizing its maneuvers-which suggests that they trusted the car because they had anthropomorphized it. Mahadevan et al. [38] have also observed positive attitudes towards human-like interaction, using a virtual robotic driver in the windshield. However, they [38] mentioned that anthropomorphic cues such as animated face or eye gaze can be difficult to interpret. Similarly, Löcken et al. [39] described that adding eyes to the car to simulate eye contact did not provide a clear signal to cross the road and caused an effect known as uncanny valley in human-robot interaction [46]. Nevertheless, many manufacturers including Jaguar Land Rover [47], Toyota [48], and Semcon [49] apply the eye contact and smiling concept to their AVs. It shows that it could improve confidence if the AV makes eye contact with pedestrians to show that they have seen them, and they are safe to cross the street.

In summary, research and concept studies by manufacturers have shown that visual communication can support interaction between $\mathrm{AVs}$ and vulnerable road users (pedestrians). Due to high demand, we have focused our studies (see Sections 4-6) for the exterior category in this area and have attempted to apply and extend them specifically to the automated shuttle bus use case.

\subsection{Interior of the Automated Shuttle Bus}

As for advances in the interior of automated shuttle buses, different areas relating to user experience (UX) and acceptance, communication and interaction needs, and interior atmosphere were identified in related work and will be discussed in the following section.

\subsubsection{Aspect \#1 User Understanding}

The first influence relates to the different user groups which value different aspects throughout the interior experience [50]. Lundquist [50] used the example that a tourist wants understandable information about the surrounding to localize better and more easily, whereas a commuter needs reliable information about traffic conditions, delays, or changes. In addition, according to Vesa [51], users are driven by different motivations to take a shuttle bus. Knowing these provides the opportunity to target some motivations especially in the interior [51]. Furthermore, different user groups engage with different activities within the bus. Knowing what users are currently doing within the shuttle and what they want to do in the future, provides the opportunity to design richer experiences for specific activities [50]. The "Mercedes Future Bus"-concept, for example, offers wireless smartphone charging spots within the bus [52]. These different wants, needs, activities, and 
motivations of the users must be taken into account when thinking about future interior designs for an automated shuttle bus.

\subsubsection{Aspect \#2 Context Dependency}

The next aspect relates to making the automated shuttle bus a holistic experience for the passenger. Moser [53] explains that when taking such a shuttle there are different system touchpoints along the customer journey. For example, checking the schedule at home, waiting at the bus stop or sitting inside of the bus [53]. As researchers, we endeavored to observe the bus experience as a customer would. This included creating customer journeys in order to identify relevant interior touchpoints and their complementary exterior touchpoints. See Section 3 to see how additional insights gained during the pre-study. Furthermore, it is important to consider different travel scenarios. Users might take the automated shuttle bus in order to get to different places at different travel times. Knowing where, when, and why people tend to use the bus, provides the opportunity to enhance the interior for specific scenarios [5]. For example, the experience for the scenario of rush hour work traveling could be differently designed than the experience in non-rush hour sightseeing.

\subsubsection{Aspect \#3 Communication and Interaction}

According to Lundquist [50] a pleasurable ride builds on trust, control, safety, and efficiency. People still lack trust in automated/autonomous systems and prefer a feeling of control about where they are going. Furthermore, ensuring that people feel safe throughout the journey will lead to more trust in the system [50]. Knowing when and why people feel safe, provides the opportunity to optimize the interior in that way. Therefore considering the feelings of trust, control and safety of the users is important when designing an automated shuttle bus. This can be solved by, for example, using a clear communication medium in the interior which makes it easier for travelers to see where the bus is going and why it reacts the way it does in certain situations. Another aspect of the communication and interaction influence is to consider user input and system output. Lundquist [50] mentioned that intuitive user input interactions and valuable system outputs lead to an overall acceptance. Furthermore, multimodality plays an important role in conveying information in the most efficient and intuitive way to the user [50]. This can be realized by, for example, visually presenting information about the next stop to the user and giving an audio/speech signal when the next stop has been reached.

\subsubsection{Aspect \#4 Atmosphere Enhancements}

Creating different ambiences, provides the opportunity to intentionally control the interior user experience. This includes adjusting design aspects like lighting, materials, smell, and sound according to different scenarios. The automated shuttle bus Gacha [54] for example offers a lounge-type relaxing ambience in the morning to get the day started, whereas the Mercedes Future Bus [43] offers an upbeat colorful social ambience in the evening. Additionally another influence of atmosphere in the bus is the seating arrangement. According to Köhler et al. [55], it is seen as an integral part for interior design. The results discussed in this paper showed that people prefer a feeling of control about where they are going, and therefore had a preference for forward-facing seats. In addition, people were less likely to be concerned about suffering from motion sickness when looking in the direction of travel [55].

\subsubsection{Aspect \#5 Service Offerings}

The last influence approaches the topic of service offerings. For example, the inclusion of external devices in the interior experience brings various opportunities. They can be used for on-demand applications, entertainment personalization or ticketing solutions. EasyMile [56], for example, already offers a smartphone concept for an on-demand service that can be easily adopted by transit agencies/public transport operators and integrated 
into their trip planning solution. Furthermore there is potential of improvement by considering real-time fleet management as, according to Bucchiarone et al. [5], the real-time and dynamic fleet management of automated shuttle buses is a main problem. Therefore, public transport operators need to manage their fleets in the most efficient way to provide an optimal customer transportation system. To support this, Easymile [56] already offers EZ Fleet, a traffic management solution to manage and coordinate shuttle buses externally. Another idea for more fine-grained planning would be to offer in-bus user tracking via unique IDs to enable the operator to manage their fleets more efficiently based on utilization.

\subsubsection{Aspect \#6 Interior Development}

Typically, in (manually driven) vehicles, the control required by the driver restricts the static design of interior concepts (e.g., position, type, reach of seat, controls, and displays). Dynamic elements such as rotating seats are not allowed. Many of these restrictions no longer apply to automated driving, especially as a passenger in an automated shuttle bus. Although there are many potential improvements that can be applied to the interior design of conventional buses or train compartments, e.g., [57,58], these two examples can serve as a foundation for the interior design of automated shuttle buses. The current problem with the concept development for automated shuttle buses is that there are no known concepts that work well for this use case. Additionally, there is mutual dependency between passenger-interior interaction in these concepts, leading to a "chicken-egg dilemma". This is due to user behavior changing with different prototypes, not to mention widespread inter- and intra-individual differences. Ref. [59] recommends an iterative user-centered interior development process to resolve this deadlock.

Due to these many possibilities, the focal points to be set for the development of novel, future-oriented interior concepts (cf. main study, Section 6) are to be reduced to the most important aspects within the framework of preliminary studies (including on-site research, Section 4 and online surveys of the general public and expert interviews, among others, Section 5).

\section{Methodology and Research Approach}

Throughout the project, the researchers followed the User Centered Design (UCD) [60] approach. UCD is a multidisciplinary design approach based on the active involvement to improve the understanding of user and task requirements, and the iteration of design and evaluation. According to ISO 9241-210 [60], UCD is defined as a development process that aims to make systems usable by focusing on the fundamental needs of users. The individual phases are executed in an iterative pattern, to incrementally improve the design and develop a solution that meets the user requirements in the end.

Applying the UCD process, the research approach followed in this project was threestage, as illustrated in Figure 1. As a first step, the research group conducted a site visit in Kelheim, a small town in Bavaria, Germany where automated shuttle buses are already operated in public transport in test mode. The aim was to get initial insights into this technology, observe users, and identify problems (Section 4). Next, refinement of the findings from phase 1 was performed through preliminary studies (Section 5) and finally, the findings from the preliminary studies served as input for the implementation of specific concepts and investigation within the main studies (Section 6). Decisions for a concrete method were made collaboratively in the group of researchers based on related work analysis, discussions and finally majority voting. 




Figure 1. Overview and relationship of the individual studies (Image source: own illustration).

Regarding the research method, we decided against virtual approaches and in favor of field studies (embedded in a mixed design with additional qualitative methods, as suggested by [61]). For the development of user interfaces, a realistic interaction behavior with high immersion plays a major role. Meanwhile, augmented and virtual reality has a lot of potential for user research due to its increasing immersion [62] and has already been used, e.g., to investigate interaction concepts for eHMIs of automated vehicles [39]. Nevertheless, for the actual work we wanted to perform user studies with automated shuttle buses in real-life and use the (experience with) existing technology as a basis for further developments. This was negatively affected by COVID-19 (but lab studies with AR/VR headsets would have also been subject to these limitations).

\section{Phase 1: On-Site Research in Kelheim}

As a first step (phase 1 of the UCD [60]), we conducted an on-site visit to Kelheim, where automated shuttle buses are used in public transport. The goal was to get first "real life" impressions and early insights of the vehicle, which could serve as a basis for the ideation process and definition of the emphasis for the pre-studies. Observations (shadowing) were carried out and additional informal conversational interviews with pedestrians, drivers, passengers, and the operators were conducted.

\subsection{Findings for the Exterior of the Automated Shuttle Bus}

Through the on-site research three particularly noticeable problem areas were identified for the exterior of the automated shuttle bus ( $\rightarrow$ main problems collected from the pre-study exterior, see Section 5.2.2). First, communication and interaction with other road users, in particular with other drivers and pedestrians, was identified as confusing, because the bus does not provide other road users with the necessary information. The automated shuttle bus does provide signals when it starts moving (ringtone and flashing lights), but these do not seem to be sufficient. In situations with unclear priority rules, there is uncertainty as to whether the bus is driving or stopping. Therefore the operator typically stops the bus manually and communicates via gestures. Secondly, there seem to be problems caused by poor or insufficient information provided at the bus stop. People who see the bus coming from a distance often do not know if it stops and if they are in the right place to be picked up. Thirdly, it was stated that the people of Kelheim are annoyed by the shuttle bus because it runs very slowly and causes traffic jams (slow operation). It was mentioned that "[...] the route is too short and you can walk the distance faster". At the moment, the bus seems to be used mainly by tourists as a kind of attraction. These types of statements were also made at other deployments of automated shuttle buses, e.g., in Bad Birnbach. Despite these statements, the slow speed was also found to be a crucial factor for trust in this new technology [2] (p. 202). 


\subsection{Findings for the Interior of the Automated Shuttle Bus}

Furthermore, for the interior of the automated shuttle bus some problems $(\rightarrow$ opportunities for improvement to be used in the pre-study interior, see Section 5.3.2) were identified. The most noticeable opportunity was the unpleasant seating direction and limited space. Three of the total of six seats were oriented against the direction of travel, resulting in motion sickness [63] for a large number of people. This aspect is directly related to the generally small size of the interior of the automated shuttle bus. This is particularly evident in the two rows of seats that have little space between them and do not offer enough personal space. Additionally, these two rows of seats offer no possibility for passengers to store personal items such as bags. The interior design language of the automated shuttle bus, which is not clearly defined, offers further potential for improvement. The design language seems rather random and not well thought-out with a current mix of different design styles and materials. The lack of consistency leads to an overall lack of ambience and few characteristics that promote well-being among passengers. The third problem area lies in the communication and presentation/visualization of information. Currently, the automated shuttle bus communicates information only visually via an overhead display. This purely visual presentation may not be sufficient and should be supplemented by an additional form of information presentation, such as audio announcements. Especially for persons with disabilities, the current form of information is insufficient.

\section{Phase 2: Preliminary Studies to Refine the Findings from the On-Site Research}

Based on research of related work and the findings of the on-site research in Kelheim, for the second phase of UCD [60] the project team designed a set of low-fidelity studies, separately for the aspects of interior design and external communication, in a joint vote. The studies were each designed applying appropriate methods.

\subsection{Methods, Together for Interior/Exterior}

As suggested by [61], a mixed-methods approach was followed, collecting both qualitative (different semi-structured interviews) and quantitative (online questionnaire) data. In the interviews, general questions, positive and negative aspects, advantages, disadvantages, experiences, wishes, as well as design-suggestions about automated shuttle buses in relation to the interior and exterior were asked. The preliminary studies on exterior and interior were conducted together. Only the creative workshop, as it was very specific, was conducted separately/individually. In the online questionnaires, questions were inserted in clusters for the two areas and separate question blocks were designed for the semistructured interviews. To avoid redundancy in the description, we have also described the jointly conducted methods together here.

\subsubsection{Expert Interviews}

The first (qualitative) method applied were semi-structured expert interviews with operators of automated shuttle buses in Bad Birnbach. This is the place where the first regular operation of an automated shuttle bus in Germany has already been introduced in 2017, thus, shuttle bus operators have wide experience on their advantages and disadvantages. In total six participants (two female and four male) aged between 25 and $58\left(M_{\text {age }}=49.00\right)$ years were interviewed. Feedback for both interior and exterior aspects was queried.

\subsubsection{Interviews with Experienced Customers}

In order to not only find out the opinion of the experts but also of the real users, additional interviews with experienced customers (persons who drive regularly with the automated shuttle bus) were conducted. Three participants (two female and one male) aged between 24 and $54\left(\mathrm{M}_{\mathrm{age}}=36.67\right)$ years took part in the semi-structured interviews. 


\subsubsection{Online Questionnaire}

Additionally, an online questionnaire was prepared in Google Forms and distributed across diverse online channels. A total of 305 participants ( 125 female, 177 male, 1 diverse, $2 \mathrm{~N} / \mathrm{A} ; 59$ in the age group "up to 20 years", 202 in the age group "21 to 35 years", 29 in the age group " 35 to 50 years" and 15 in the age group " 51 to 65 years") completed the questionnaire voluntarily. The questionnaire contained open text, multiple choice questions, as well as check boxes and questions on Likert scales. This way it was possible to gain qualitative insights, but also quantitative data.

\subsubsection{Creative Workshops}

As a fourth method, creative workshops with a representative test group were carried out specifically for exterior and interior.

\section{Exterior Workshop}

As for exterior, $(n=13)$ participants (six female and seven male) aged between 18 and $79\left(\mathrm{M}_{\mathrm{age}}=39.69\right)$ years had to perform a moodboard selection to spot the most fitting mood for the exterior design of an automated shuttle bus. Moodboards are used as an evaluation tool for emotion [64] and design [65] research. Four moodboards (collections of images that visualize certain moods/design languages) were available to choose from, see Figure 2. This method was intended to be used to evaluate the preferred, general design style. Moreover the workshop included the sketch-a-bus exercise. Therefore a template of an automated shuttle bus was created and the participants had to draw, color, and design the exterior of the bus according to their own ideas. In parallel, the think aloud method was used . Participants were asked to express their thoughts as well as justify and explain their drawings. Finally, a structured interview was conducted.
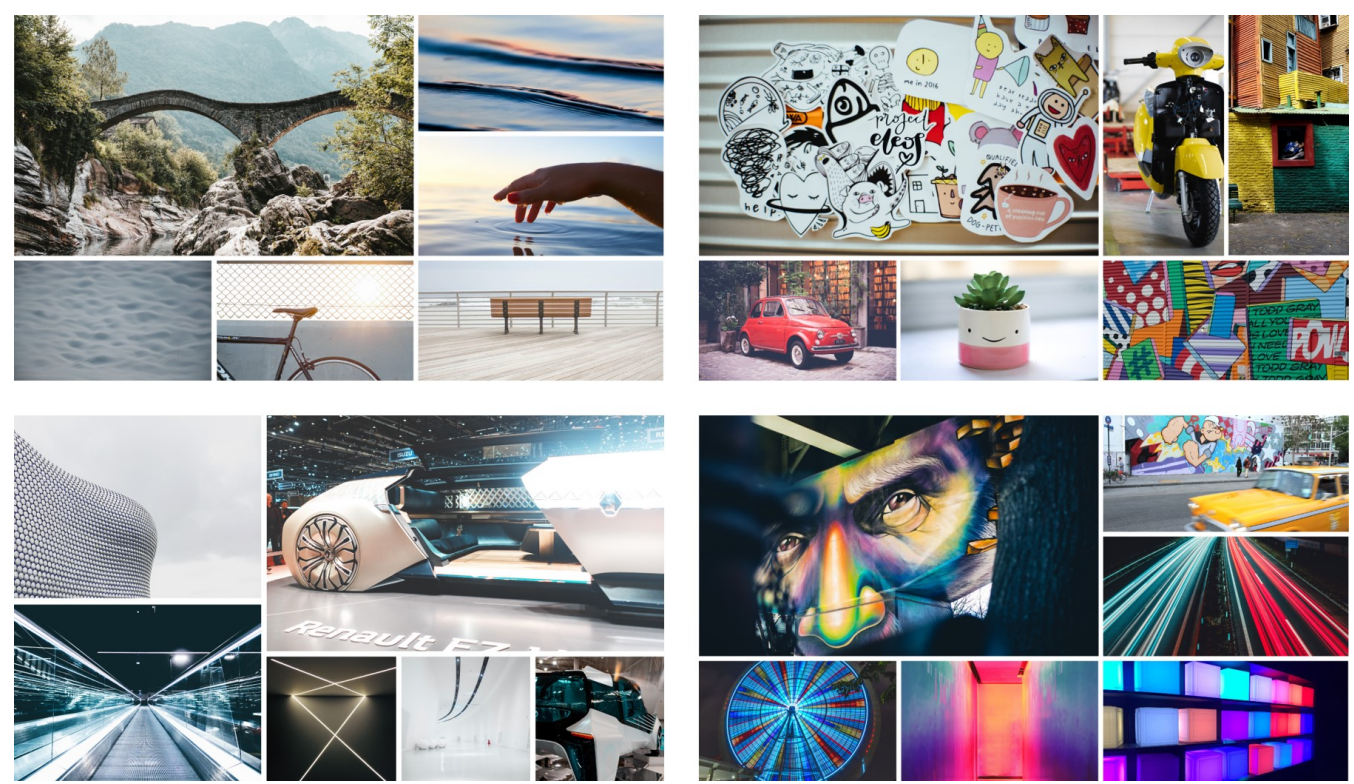

Figure 2. Moodboards from which the participants had to select in the creative workshop of the exterior team. (Top left): quiet-restrained. (Top right): childish-comic. (Bottom left): modernfuturistic. (Bottom right): strikingly-obtrusive (Image sources: Unsplash, https://unsplash.com (accessed on 29 July 2021).

Interior Workshop

Another workshop with $(n=16)$ different people (11 female and 5 male) aged between 22 and $63\left(\mathrm{M}_{\mathrm{age}}=37.63\right)$ years was conducted to gain further interior insights. To examine the expectations regarding the interior design of an automated shuttle bus, a card selection activity was conducted with a representative sample. The participants were provided with a printed-out template containing different interior atmosphere categories (design 
language, light mood, colors, sound, smell, materials, activities, and services). For each of these categories picture cards with different options to choose from were provided. This card selection exercise was complemented by a seating-layout sketching exercise, in which the participants should sketch how they envision an automated shuttle bus seating layout (see Figure 3). During this process the think aloud method was used in which the test subjects were asked to express their thoughts as well as justify and explain their card selections and layout drawings. The creative workshop was concluded with a semi-structured interview which examined the participants general experiences in public transportation as well as their expectations for an automated shuttle bus.


Figure 3. Impressions of the creative workshop by the interior team. The participants were asked to select option cards for different interior categories and place them onto the template. This was complemented by a seating layout sketching exercise (Image sources: own photos).

\subsection{Exterior of the Automated Shuttle Bus}

\subsubsection{Research Questions}

We also defined research questions for the preliminary study in advance in order to better guide its direction. However, as this was mainly qualitative research to prepare us for the main study, their rigorous evaluation was not the focus at this stage and is therefore not indicated.

- $\quad \mathbf{R Q}_{E} .1$ : How can the communication between the automated shuttle bus and other road users be improved?

- $\quad \mathbf{R Q}_{E} .2$ : How can the service offered when using the automated shuttle bus be more attractive for users?

- $\mathbf{R Q}_{E} .3$ : How can acceptance and level of trust in the automated shuttle bus be improved in relation to the exterior?

These research questions relate to the investigation of the improvement potential regarding communication, service design and trust/acceptance for the exterior design of automated shuttle buses and results from the preliminary study for these RQs are summarized below.

\subsubsection{Results}

In this section, we summarize the results of all methods used in phase 2. Different methods of analysis were used. First, descriptive statistics were calculated using IBM ${ }^{\circledR}$ SPSS ${ }^{\circledR}$ Statistics, Version 24 [66] and frequency distributions were created. Qualitative data was clustered on an affinity board (first inductively, then deductively coded).

For the exterior of the bus, four insight categories were identified, each with different insights on different subject areas. The area general aspects includes insights such as service, motivation of use, technical aspects, or target group. Concerning the motivation of use it was mentioned that a door-to-door shuttle service and the use on-demand are seen as particularly valuable. In the field of acceptance where aspects of trust, safety or joy of use are covered, we found that the presence of the operator increases the trust for the passengers. The third area exterior design includes findings about size, shape, color, lights, doors/windows or wheels. The last and for this article most important area 
communication provides information about whether communication with automated shuttle buses is necessary, what current problems there are, with whom, how, and in which situations communication is desired. Since the focus of this paper lies in this last subject-area (communication), some particularly important insights from this field are explained below.

The creative workshop, and the sketch-a-bus exercise in particular, produced a wide variety of results and turned out to be very beneficial (see Figure 4 for examples).
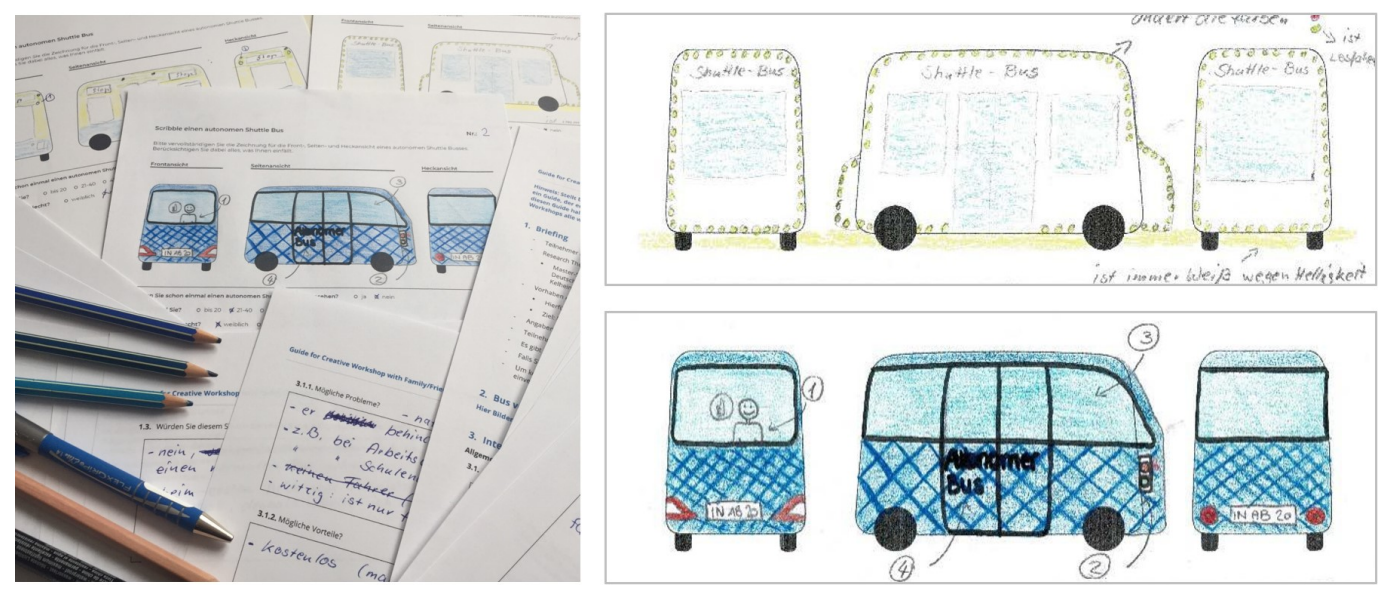

Figure 4. Impressions of the results from the sketch-a-bus exercise of the creative workshop by the exterior team. The test persons were asked to draw, color and design the exterior of the bus according to their own ideas. A template (outline of the bus) was given (Image sources: own photo/scans).

Several participants, especially experts (operators), mentioned that the "bus leads to uncertainty for other road users" and "the current communication possibilities with the environment are not sufficient" as the headlight flasher that is currently used is more likely to lead to additional confusion for other road users. They are unsure of what the bus will do next-will it stop or will it continue? There is also uncertainty about how other road users should behave correctly in the vicinity of the bus and what distance they have to keep to the bus. Currently the operators counteract this problem by interacting with gestures (e.g., waving) which are unfortunately often misunderstood and very difficult to see from the outside due to the mirrored windows. It was additionally found in the online questionnaire that of those who have already had experiences in the interaction with automated shuttle buses $(n=46), 63 \%$ felt they were negative, $22 \%$ neutral, and only $15 \%$ perceived them positively. Respondents stated that they were particularly bothered by the fact that the bus often "stops for no apparent reason" which shows that other road users cannot understand how the bus is acting and for what reasons. All these findings encourage us to believe that there is a profound need for communication between the automated shuttle bus and other road users.

Referring to the situations in which the bus should communicate, participants explained that communication would be "particularly important when interacting with weaker road users" for example "at bus stops when stopping and approaching".

Furthermore it was expressed by several people that a visual "communication with lights and displays would be useful". Quantitative data from the online questionnaire underline this statement as $76 \%$ of the participants think that lights are the most useful way of communication followed by $58 \%$ for displays (see Figure 5). Further results of the creative workshop show the desire for easily understandable light signals, e.g., with color coding that is already known from the traffic light system (red and green). Concepts that communicate via auditory signals were least often seen as meaningful (last two places) which can be explained on the basis of qualitative data, since sounds or language are often perceived as unpleasant, aggressive or even as noise pollution. 


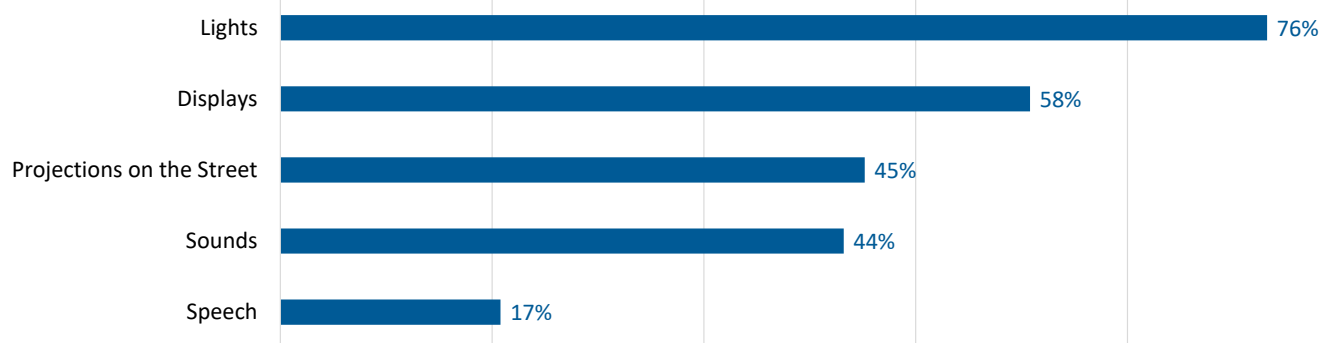

Figure 5. Frequencies of the answers to the question "What kind of communication do you think is useful?" in the online questionnaire $(n=305)$ (Image source: own illustration).

\subsection{Interior of the Automated Shuttle Bus}

\subsubsection{Research Questions}

We also defined research questions for the interior category for the preliminary study to better determine its direction in advance. As with exterior, systematic data collection/evaluation was not a priority, but rather it was important for us to gather general insights for the main study.

- $\mathbf{R Q}_{I} .1$ : How can the overall user experience inside the automated shuttle bus be improved?

- $\quad \mathbf{R Q}_{I}$.2: How can the user acceptance of passengers of the automated shuttle bus be improved?

- $\quad \mathbf{R Q}_{I}$.3: How can human-machine communication and interaction in the interior of the automated shuttle bus be improved?

- $\quad \mathbf{R Q}_{I} .4$ : How can the indoor atmosphere in the automated shuttle bus be improved?

These research questions for the preliminary study are related to the investigation of potential improvements in user experience (UX), acceptance, communication needs, and interior design (mood, atmosphere) for the interior category of automated shuttle buses. The results of these RQs are summarized below.

\subsubsection{Results}

Six insight categories were identified for the interior of the automated shuttle bus. The category interior activities includes insights such as what type of activities users prefer in public transport or the desire for certain on-demand information such as sightseeing options. Concerning the activities, relaxation and entertainment were in particular mentioned as valuable and desirable for the customers during the ride. In the field of interior acceptance we found that the acceptance can mainly be increased by an attractive interior ambience, increased security measurements, and information displays. The area of user feelings and opinions has shown that the passengers mostly prefer privacy in the bus, but also like to communicate if they ride together with someone familiar. The category interior functionalities included insights such as current functional equipment having the potential for improvement. Furthermore, example of this would be having controllable overhead heating systems in addition to having the possibility to open the windows. The category of interior communication included aspects about what types of information need to be communicated within the shuttle bus interior. According to participants, a combination of passive (screen) and active (announcement) communication is best for important information. The last area of interior design included insights such as the users preferring an innovative, yet simple interior design that provides enough space for the storage of belongings. Since the interior research results of this paper lie mostly in the last two subject-areas (interior design and communication) some particularly important insights from this field are explained below.

According to the interviewed operators $(n=6)$ and their experience, the current interior design language and atmosphere of the shuttle bus in Kelheim and Bad Birnbach 
(type EasyMile EZ10) is perceived as simple, boring and uncomfortable and is improvable. The online questionnaire $(n=305)$, on the other hand, revealed in a rating of different interior design examples a tendency of users towards innovative (53\%), futuristic (44\%), and simple interior designs (44\%), as illustrated in Figure 6.
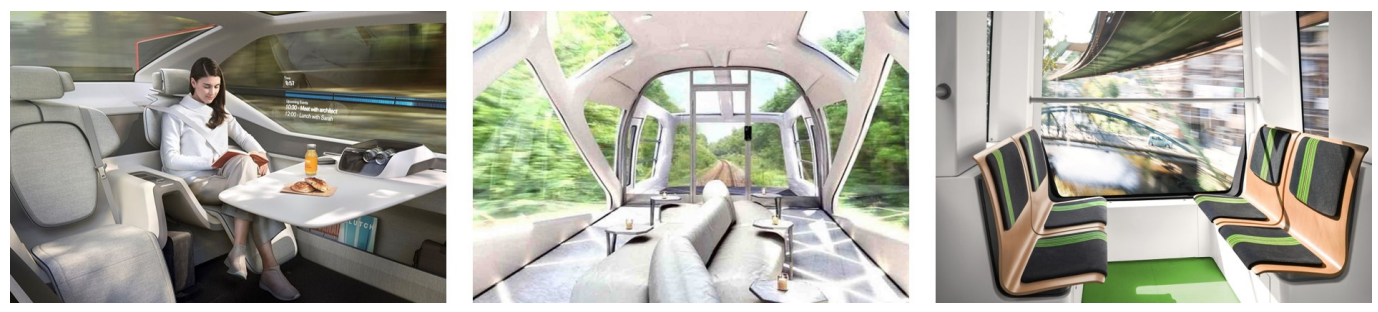

Figure 6. The three most chosen interior design examples form the online questionnaire. (Left): Innovative interior example. (Middle): Futuristic interior example. (Right): Simple interior example (Image sources: Internet).

After visually introducing and showing pictures of the interior of the EasyMile shuttle in the online questionnaire, the participants were asked to rate different aspects related to the interior of this bus, such as materials, colors or forms with questions on a Likert scale. In particular the rating of the seating (31\% neutral, $17 \%$ bad, $3 \%$ very bad) indicated possibilities for improvement (see Figure 7). Additionally, the semi-structured interviews of the creative workshops uncovered that the current seats are too narrow and driving backwards is not desired as well.

HOW DO YOU LIKE THE SEATING OPTIONS OF THE SHOWN AUTOMATED SHUTTLE BUS (EASYMILE)?

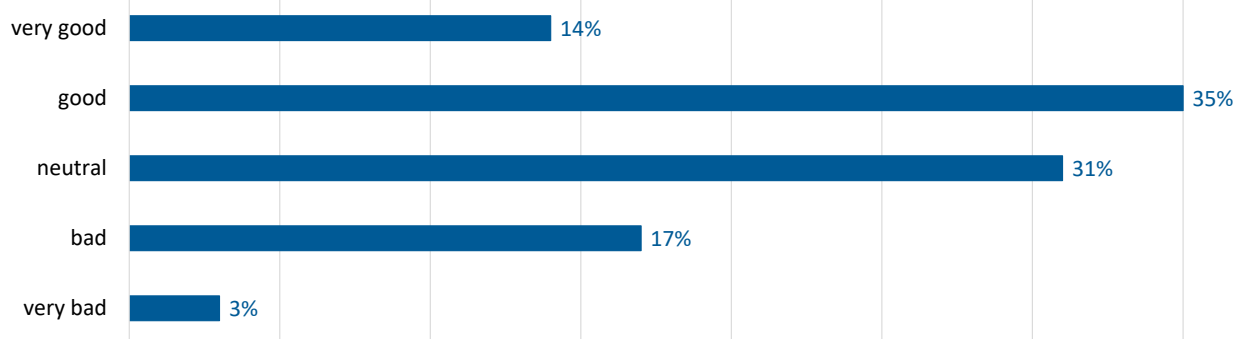

Figure 7. Bar chart showing the rating of the seating in the online questionnaire $(n=305)$ (Image source: own illustration).

In reference to the interior communication, experienced customers described that the automated shuttle bus currently only displays information visually on an over-head display. As stated by these customers as well as multiple participants of the creative workshop, using passive and active modes of communication such as screens and announcements are desirable when relaying important information.

In addition, the interior creative workshop produced a wide variety of results and turned out to be beneficial. Based on the card selection template method the interior team was able to define two clear interior atmosphere directions. These were visually presented with moodboards. The first direction was named "Nature Green" (Figure 8) and the second was named "Sky Blue" (Figure 9). Each moodboard was complemented by keywords that were mentioned by the participants to the individual template categories during the think aloud method. 


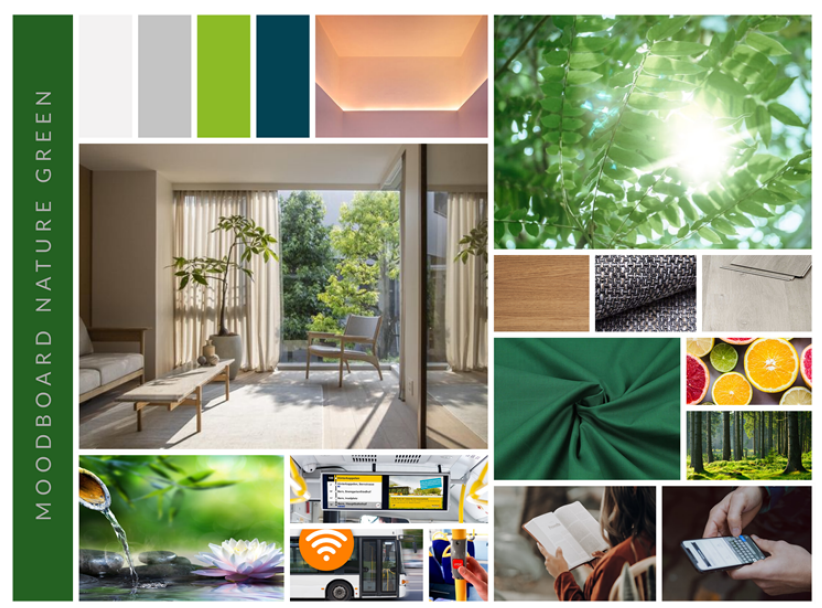

DESIGN LANCUAGE: bright, green rooms with natural light

LIGHT MOOD: bright, natural, warm, fresh

COLORS: neutral, friendly, light, green: positive and fresh

SOUND: calm and discreet sounds; played in the background; wellness music

SMELL: citrus fruits, forest, fresh, not aggressive but subtle and clean

ACTIVITIES: cell phone, reading

MATERIALS: robust and easy to clean materials; cotton: comfortable fabric; wood for the floor: attractive, but delicate and expensive

SERVICES: digital display, WLAN, stop button

Figure 8. The resulting "Nature Green" atmosphere Moodboard of the interior creative workshop (Image sources: Internet).

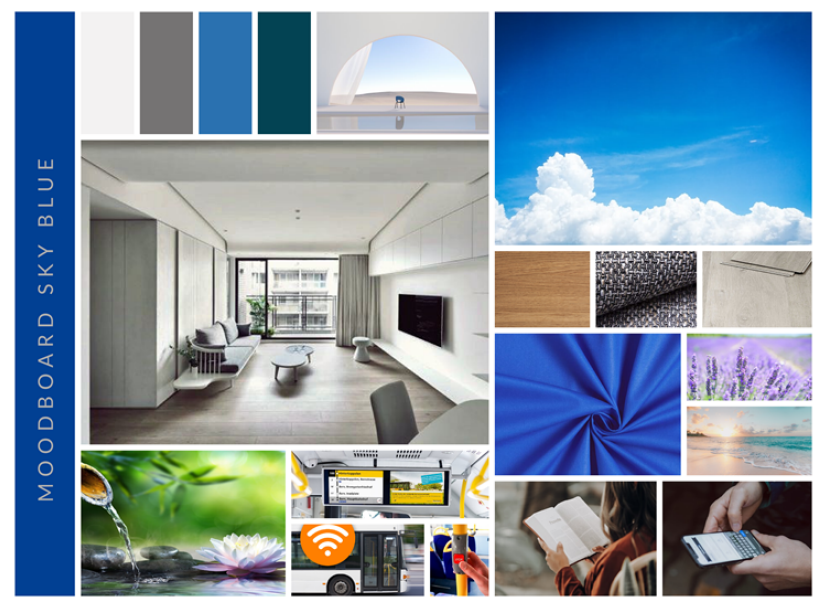
DESIGN LANGUAGE: open, modern, simple,
minimalist, spacious

LIGHT MOOD: bright, natural, modern

COLORS: neutral colors; blue (mostly for seats); blue: progressive and innovative, Scandinavian

SOUND: calm and discreet sounds; played in the background; wellness music

SMELL: sea, lavender; fresh, not aggressive but subtle and clean

ACTIVITIES: cell phone, reading

MATERIALS: robust and easy to clean materials; cotton: comfortable fabric; wood for the floor: attractive, but delicate and expensive

SERVICES: digital display, WLAN, stop button

Figure 9. The resulting "Sky Blue" atmosphere Moodboard of the interior creative workshop (Image sources: Internet).

According to the insights from the preliminary study for interior the three factors (1) seats, (2) interior layout/appearance, and (3) information presentation were identified with the most potential for improvement. Thus, these factors were further taken into account in the conception of the main study.

\section{Phase 3: Main Studies to Investigate Specific Interior/Exterior Concepts}

Based on the insights gained from the related work analysis, the on-site visit/research (phase 1, Section 4) and the preliminary studies (phase 2, Section 5), different concept ideas were developed for both areas of investigation (interior, exterior) applying an iterative process. The final concepts were implemented using prototypical methods and evaluated in the main studies as summarized below. Results are presented in Section 7 and discussed in Section 8.

\subsection{Exterior of the Automated Shuttle Bus}

\subsubsection{Method}

After clustering the top insights from the pre-study, design thinking methods (formulating jobs-to-be-done and how-might-we-questions) helped us to specify problem definitions. All decisions made (e.g., definition of the three key situations and implemented concepts) are based on insights from the previous phases.

Three key situations, i.e., situations in which communication between the automated shuttle bus and pedestrians is of particular importance, were defined: 
- Virtual bus stop: In this key situation the bus pulls over to the right to stop at a virtual bus stop (a flexible stop requested by passengers so that they can board or get off wherever they want). This scenario is based on the researched motivation of use (door-to-door and use-on-demand scenarios), which is why virtual bus stops are quite conceivable. The uncertainty of other road users whether and why the bus will stop should be counteracted.

- Security zone: If objects are detected in this sensor area around the bus a certain action (usually a stop) is carried out. We chose this second key situation as other road users are unsure how to behave correctly in the vicinity of the bus and what distance they have to keep.

- Entry/exit process: The process of getting on and off at a bus stop: passengers get off first and then new passengers get on. This key situation is justified with the insight that people wish clear interaction with the bus especially at bus stops.

The concepts developed in the three key situations facilitate communication between pedestrians and the automated shuttle bus in different ways. The two concepts that will be developed and compared against the baseline (BA; current state-of-the-art) are as follows:

- Aura (AU): A subtle communication concept that uses different colors for the communication with the bus users. We decided on the aura concept as visual communication using easily understandable light signals with already known color codes (red and green) as this is seen as particularly useful. This concept idea was already drawn by one participant in the sketch-a-bus exercise (Figure 4, top right).

- Avatar (AV): A direct communication concept that uses a human-like avatar which communicates with gestures and facial expressions. As the bus driver/operator increases the trust for the passengers it is to be replaced with a virtual representation in order to keep the trust level high. This concept also emerged during the sketch-a-bus exercise (Figure 4, bottom right).

As a prototyping method an interactive user journey (telling a story in individual subsequent pictures) with animated key situations was chosen. "Tony" was introduced into the story as the protagonist. He was supposed to use the automated shuttle bus to go to town, shop, and eventually return home. Tony interacts with the bus in the different previously described key situations.

Implementation of the "Aura" Concept in the Story

In the first key situation, the aura of the bus turns blue as the bus approaches the virtual stop (Figure 10, left). The blue color is meant to tell Tony that the bus will stop for him. As soon as the bus arrives at the virtual stop the color changes to green to communicate to Tony that he is allowed to get on. In the security zone situation when Tony is standing too close to the bus, the aura pulses red to signal to him to move away from the bus (Figure 10, middle). In the entry/exit process the aura is red at first to show that other people first get off the bus. Then the aura turns green to show Tony that now he is allowed to enter the bus-and therefore can step into the security zone around the bus (Figure 10, right). 



Figure 10. Aura concept in the three different key situations. (Left): Increasingly blue light when approaching the virtual bus stop conveys that the bus will stop to allow passengers to board. (Middle): Red pulsing light signals that someone is standing in the security zone. (Right): Green light signals that people are allowed to board (Image sources: own illustration).

Implementation of the "Avatar" Concept in the Story

For the avatar concept the method of communication is different. In the first key situation (virtual bus stop) the avatar waves at Tony and displays a greeting and his name on the windshield to signal that the bus will stop for him (Figure 11, left). In the security zone situation, the avatar uses a pushing hand gesture and an angry facial expression to signify to Tony to increase the safety clearance (Figure 11, middle). In the third key situation (entry/exit process) the avatar shows Tony a stop hand to tell him he must wait and let other passengers get off. As the passengers get off, he virtually starts drinking coffee to signal that he is waiting and everybody can get in (Figure 11, right). As the bus wants to depart, the avatar turns around and disappears to indicate the bus is about to leave.



Figure 11. Avatar concept in the three different key situations. (Left): Avatar waves and greets the passenger when approaching the virtual bus stop conveying that the bus will stop to allow passengers to board. (Middle): Avatar uses gestures (stop hand) and facial expressions to signal that someone is standing in the security zone and should leave it. (Right): Waiting (coffee drinking) avatar signals that the bus is waiting to let people board (Image sources: own illustration).

\subsubsection{Research Questions and Hypotheses}

As for the exterior, the two concepts avatar (AV) and aura (AU) are compared against the baseline (BA) condition (current solutions, i.e., turn signals and hazard warning lights only) to address the following research question $(\mathrm{RQ})$ and hypotheses $(\mathrm{Hs})$.

$\mathbf{R Q}_{E}$ : How is the UX of an automated shuttle bus influenced when interacting with different communication concepts as a pedestrian?

- $\quad \mathbf{H}_{E .1}$ : Pedestrians give more positive overall UX ratings (indicated by the latent dimensions attractiveness, pragmatic quality, and hedonic quality) in the variants aura and avatar in contrast to the variant baseline.

- $\quad \mathbf{H}_{E .2}$ : Pedestrians give more positive ratings in the individual situations (indicated by the dimensions attractiveness, pragmatic quality, and hedonic quality) in the variants aura and avatar in contrast to the variant baseline. 
- $\quad \mathbf{H}_{E .3}$ : Pedestrians perceive communication as more clear in the variants aura and avatar in contrast to the variant baseline.

\subsubsection{Study Design and Participants}

In total, 24 participants ( 8 female and 16 male) aged between 19 and $79\left(\mathrm{M}_{\mathrm{age}}=35.67\right)$ years participated in the study (see Figure 12 for an overview of the study design).

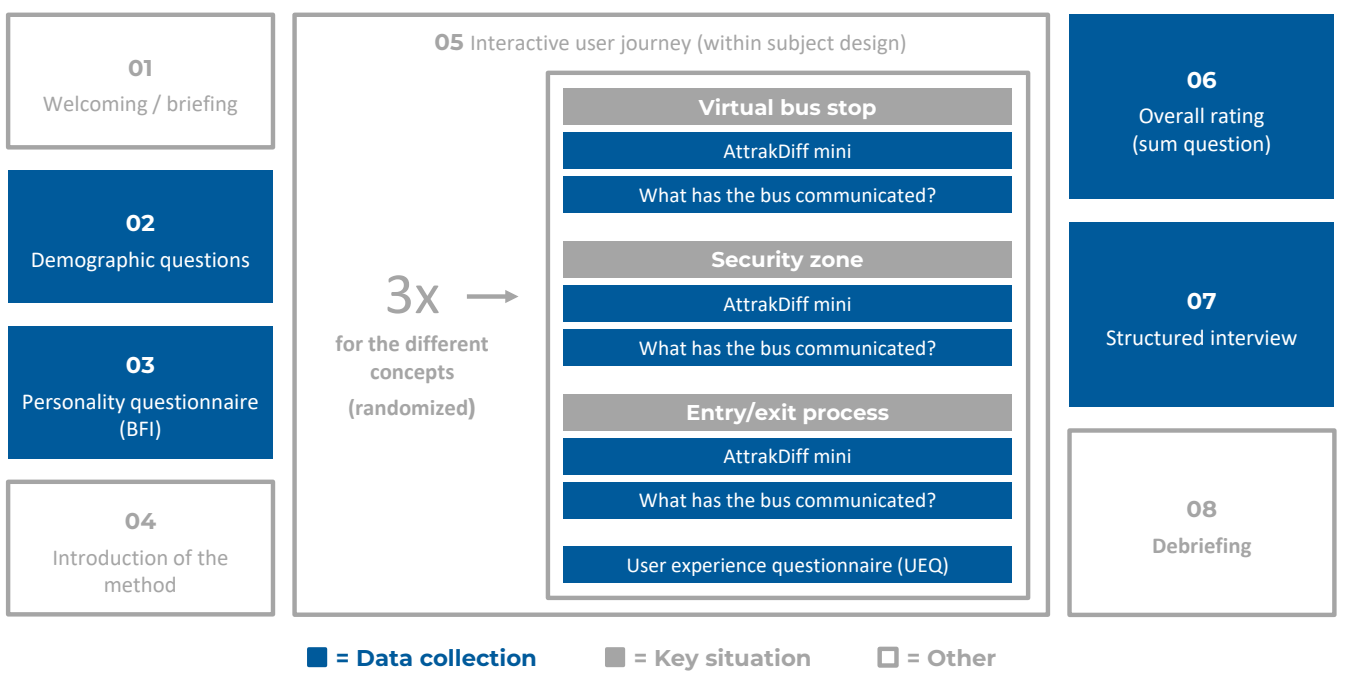

Figure 12. Overview of study design for the main study in the exterior category (Image source: own illustration).

The online tool LimeSurvey Version 3.12.1+180616 [67] was used for storytelling and integrating the intended questionnaires. A within-subjects design was used and each participant was confronted with all three variants of the IV "type of communication" (three levels: BA, AU and AV). For each of the conditions, the participant had to evaluate the three key situations (so, $3 \times 3=9$ overall). To compensate learning effects, the order of the presentation of the communication conditions was randomized. Since the three core situations tell an overarching story (stages of a journey), their order remained constant. Quantitative UX-related data [68] were collected using the standardized questionnaires AttrakDiff mini [69] and UEQ [70]. In order to be able to evaluate the clarity of communication, the question "What has the bus just communicated?" was asked several times throughout the study. Additionally, a sum question (dividing 100 points across the three concepts-the higher the score the better the rating) was asked. Qualitative data was collected using a structured interview that included the following:

- Reason(s) for the distribution of scores in the sum question.

- $\quad$ Likes/dislikes about the concepts.

- $\quad$ Suggestions for future improvement.

- Further suggestions, comments or ideas.

\subsubsection{Procedure}

An experimenter was present throughout the course of the study, in order to guide the participant and answer upcoming questions. The survey started with a welcome screen and an introduction by the experimenter followed by demographic questions. To gain more information about the personality of participants, the Big Five Inventory (BFI-10) [71] was used. The inventory had to be filled by participants to allow for more fine-grained analysis of results. In particular, the influence of openness (e.g., due to a median-split of respondents) to (technological) innovations (as measured by the BFI dimension "openness vs. closedness to experience") was considered interesting in preparation. In the later phase 
of the evaluation, however, this aspect was not considered further due to an insufficient data set for statistical evaluations.

Before starting with the main part of the study, the protagonist Tony and the functionality and area of application of the automated shuttle bus were introduced. The participant then experienced the stories for each communication type in a randomized order. After each key situation (three times per concept, nine times overall), the participants had to (1) answer the question "What has the bus just communicated?" and (2) fill out the AttrakDiff mini based on the situation just seen. At the end of each of the three communication concepts (BA, AU, AV), the concept as a whole was evaluated using the UEQ [70]. Afterwards, the next concept was presented following the same procedure. Once the participant went through all three concept-stories, the concluding sum question had to be answered. Finally, the study was concluded with a structured interview and debriefing.

\subsection{Interior of the Automated Shuttle Bus}

\subsubsection{Method}

In the previous phases, the three aspects (1) seating, (2) interior design/appearance, and (3) information presentation were identified as the areas with the greatest potential for improvement. These were used as basis for further investigation and were first subdivided into several subcategories in order to focus on specific parts in more detail.

The category seats includes the subcategories shape, arrangement, and functionality. Arrangement is further divided into body position, seat placement, and seating direction. Interior layout/appearance contains the subcategories interior areas, which deals with the interior division of the bus into different sections, and design language, which investigates the overall look and feel of the interior. For the third category information presentation, we split into subcategories visual sense, which is commonly used for displaying information in buses, and other senses, which represent any other form of information presentation apart from the visual. The general course of action was to provide the participants a blank configuration template built from these categories, in addition to feature cards (see Figure 13) containing images or sketches together with a description.
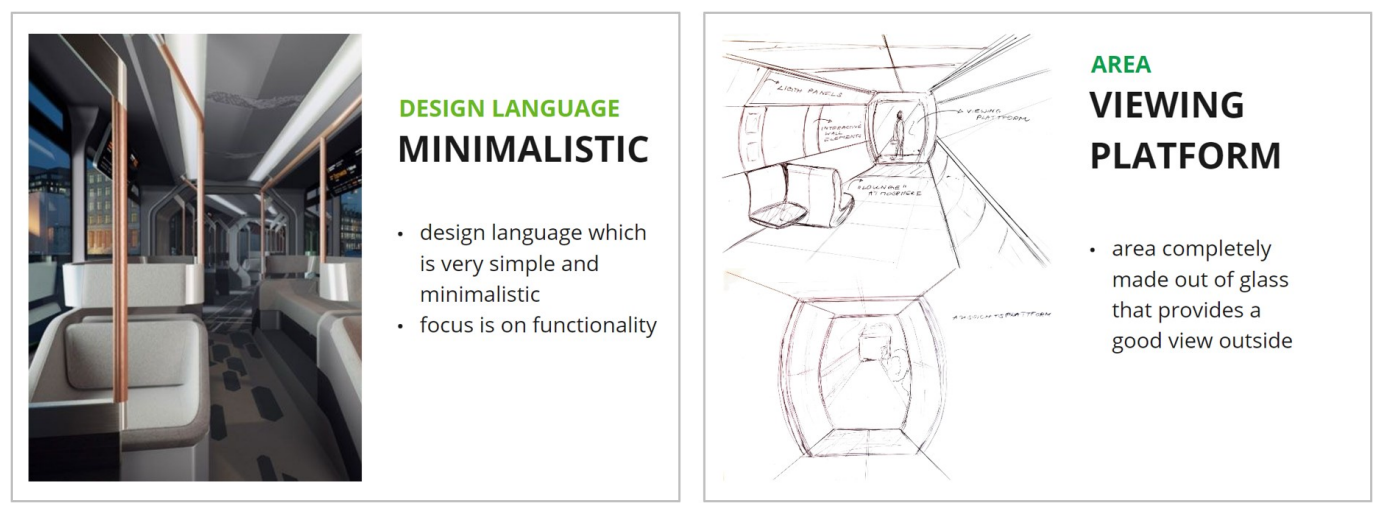

Figure 13. Examples for configuration feature cards. (Left): Minimalistic design language, (Right): Viewing platform area (Image sources-left: Internet, right: own illustration).

Moreover, we defined a usage scenario that explained why the participant is taking the automated shuttle bus, in order to facilitate a better understanding of the situation. Participants were asked to imagine using the shuttle bus to drive from the city center of Ingolstadt to the main train station, from which they would then take the train the Munich. It was stated that the overall journey with the shuttle will last roughly $25 \mathrm{~min}$. The feature cards were intentionally kept black and white so as to avoid any unwanted influences caused by their colorOnly the subcategory design language retained its color, as in this case it is necessary for differentiation and represents an important feature. 


\subsubsection{Research Questions and Hypotheses}

For the interior design of the automated shuttle, a remote, online study was conducted to evaluate two concept variants-one three years in the future, and one 25 years in the future. The study (see Figure 14 for a detailed overview of the study design) consisted of a semi-structured interview and a configuration section, and was conducted using the online whiteboard tool Miro [72] on the participants' computers.


Figure 14. Overview of study design for the main study in the interior category (Image source: own illustration).

We have raised the following research question (RQ) and explored the following hypotheses (Hs):

$\mathbf{R Q}_{I}$ : How do potential passengers envision the interior of an automated shuttle bus closer in the future (+3 years) compared to a concept further in the future (+25 years) and what are the reasons for this?

- $\quad \mathbf{H}_{I .1}$ : When envisioning the interior of an automated shuttle bus for the near future (+3 years), compared with the farther future ( +25 years), potential users regard their hedonic quality with significant difference.

- $\quad \mathbf{H}_{I .2}$ : When envisioning the interior of an automated shuttle bus for the near future ( +3 years), compared with the farther future (+25 years), potential users regard their pragmatic quality with significant difference.

- $\mathbf{H}_{I .3}$ : Potential passengers rate the importance of seating, interior design/appearance, and information presentation, and their subcategories, significantly differently.

\subsubsection{Study Design and Participants}

In total, 21 participants aged between 22 and 63 years $\left(\mathrm{M}_{\mathrm{age}}=35.1\right)$ participated in the interior study. The study was conducted as a within-subjects design, whereas each of the participants configured the automated shuttle bus interior twice, once for the closer in the future concept ( +3 years) and once for the further in the future concept ( +25 years). To avoid an unintentional learning effect and comparison bias, the order of the two interior configurations was randomized, and after the first configuration the finished template was hidden from the participant. The configuration itself was performed on a computer, whereas an experimenter supported the participant on request. The main focus of the study was to gather qualitative insights in an exploratory way about how potential users envision the shuttle bus interior in different time periods. Therefore, the participants were asked to think aloud during the study and were asked semi-structured interview questions after each configured category. In order to make the interior differences between the time periods comparable and visual, quantitative data was collected after each configuration 
using the UEQ [70]. Once a participant went through both configurations a sum question had to be answered (distributing 100 points among the three categories - the higher the score, the more they valued the category). The gathered qualitative and quantitative results were subsequently evaluated, interpreted, and interior design recommendations (in general and for both concepts individually) were derived.

\subsubsection{Procedure}

The study started with a short welcome and a briefing by the experimenter. To gain more information about the personality of participants, the Big Five Inventory (BFI-10) [71] was conducted. For the same reasons already explained under Section 6.1.4, the results of the inventory were not subsequently used.

Following up, the configuration method and process were explained, as well as the usage scenario. The main body of the study consisted of the configuration of the interior of the automated shuttle bus. Participants received the template and had to configure it twice: once for each concept (closer, further in the future). As for the configuration process, participants were asked to select two of the given feature cards for each subcategory and place them onto the template according to their first and second priority. As stated before, participants were asked to think aloud during the study and had to answer semi-structured interview questions after each subcategory. After finishing the template, the participants were asked to rate their configuration according to the UEQ [70]. The UEQ was also conducted twice, once for the +3 years, once for the +25 years concept. After the participant finished the two template configurations the overall 100 point rating (=sum question) of the three categories was carried out, as previously explained. The last part of the study was a comparison of the two finished configuration templates next to each other accompanied with a semi-structured interview. The study was concluded with demographic questions and debriefing.

\section{Results}

The results from the main studies are presented in this section, separately for exterior and interior and further divided into quantitative and qualitative results.

\subsection{Exterior of the Automated Shuttle Bus}

We performed the descriptive and inferential statistical analyses with IBM ${ }^{\circledR}$ SPSS ${ }^{\circledR}$ Statistics, Version 24 [66]. The qualitative data was first coded inductively and then deductively.

\subsubsection{Quantitative Results}

We set the significance level to $\alpha=0.05$. Therefore, all results with $p<\alpha$ are reported as statistically significant. Since, according to Shapiro-Wilk's Test, the measures did not follow a normal distribution, we applied non-parametric tests. The Friedman test of differences among repeated measures was conducted and rendered a $\chi^{2}$ value of 174.877, which was significant $(p<0.001)$. Friedman's Two Factor ANOVA by Rank with Bonferroni correction was applied as a Post-hoc Test.

First, the overall UX ratings of the UEQ [70] (cf. Figure 15) were analyzed. When investigating the dimension attractiveness, significant differences were seen in the comparison of BA with AU $(p=0.000)$ and BA with AV $(p=0.042)$, while comparison for the concepts AU with AV ( $p=0.214)$ did not show significance. This observation also applies to the hedonic quality: we could find significant differences between BA and AU $(p=0.000)$ and BA and AV ( $p=0.000)$, but none when comparing AV with AU $(p=1.000)$. For the pragmatic quality, this looks different: when comparing BA with AU $(p=0.009)$ and AV with AU $(p=0.012)$ there are significant differences, unlike the comparison of BA with AV $(p=1.000)$ without significance. 




Figure 15. Results from the User Experience Questionnaire [70]: Attractiveness, Pragmatic, and Hedonic Quality (Image source: own illustration).

Additional information not directly referring to the hypotheses, but which nonetheless represents interesting results, is presented by the individual dimensions of perspicuity, efficiency and dependability. Together, these reflect the pragmatic quality (cf. Figure 16). $\mathrm{AV}$ has roughly the same mean values as BA. The more noticeable difference between $\mathrm{AU} / \mathrm{AV}$ compared to the BA can be seen in stimulation and novelty, which represent the hedonic quality already described.

COMPARISON OF ALL SIX UEQ DIMENSIONS

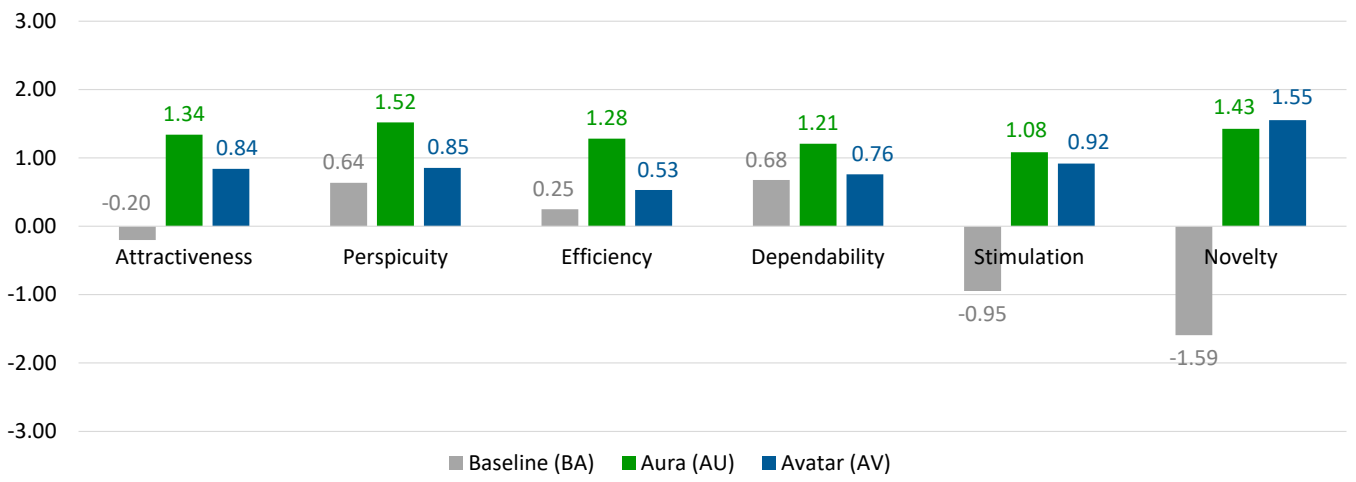

Figure 16. Results from the User Experience Questionnaire [70] with all individual dimensions (Image source: own illustration).

Second, results from the AttrakDiff mini were analyzed for each key situation individually. For the virtual bus stop, (cf. Figure 17) no trend can be seen for the dimensions attractiveness and pragmatic quality as the means of all three concepts are quite the same. Only the hedonic quality is better rated for the concepts AV and AU compared to BA.

For the situation entry/exit process (cf. Figure 18), the same was observed. No trend can be seen for the dimensions attractiveness and pragmatic quality, but the hedonic quality was rated better for $\mathrm{AV}$ and $\mathrm{AU}$.

For the security zone situation (cf. Figure 19), a trend can be seen towards a better rating for the concept $\mathrm{AU}$ in all three dimensions compared to $\mathrm{BA}$. AV seems to be perceived just slightly better or equally compared to BA. 
VIRTUAL BUSSTOP: ATTRAKDIFF DIMENSIONS ATT, PQ AND HQ

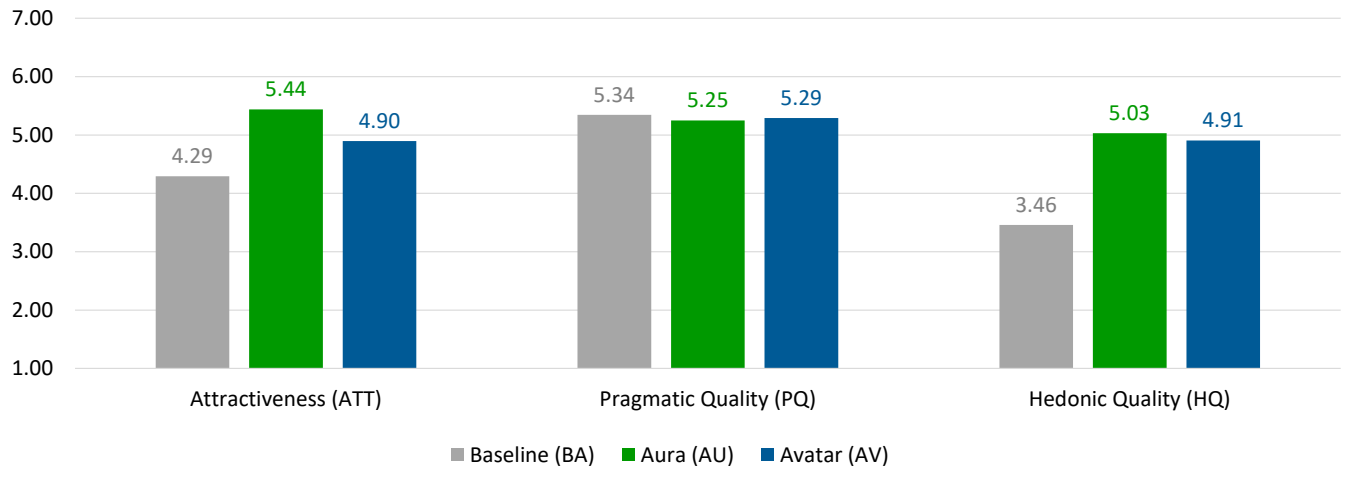

Figure 17. Results from the AttrakDiff mini for the virtual bus stop situation (Image source: own illustration).



Figure 18. Results from the AttrakDiff mini for the entry/exit process (Image source: own illustration).

SECURITY ZONE: ATTRAKDIFF DIMENSIONS ATT, PQ AND HQ

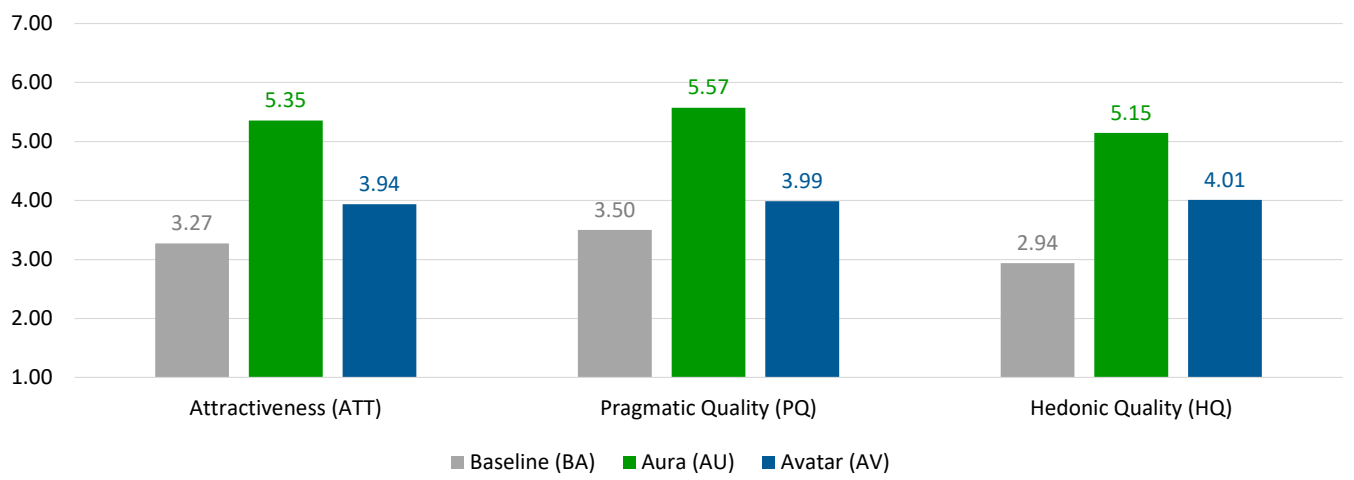

Figure 19. Results from the AttrakDiff mini for the security zone situation (Image source: own illustration).

Third, the right/wrong answers from the question "What has the bus just communicated?" were counted (cf. Figure 20). Overall, AU achieved the best results, as almost every participant answered correctly. For concept AV, especially at the virtual bus stop, the communication was not as clear, with a rate of wrong answers that was three times higher. The right/wrong ratio for BA was poor for the security zone and entry/exit process situations. Only AU leads to a clearer way of communication compared to BA. Again, not every situation tended to be more clear. For the virtual bus stop situation, BA achieved a slightly better rating. 


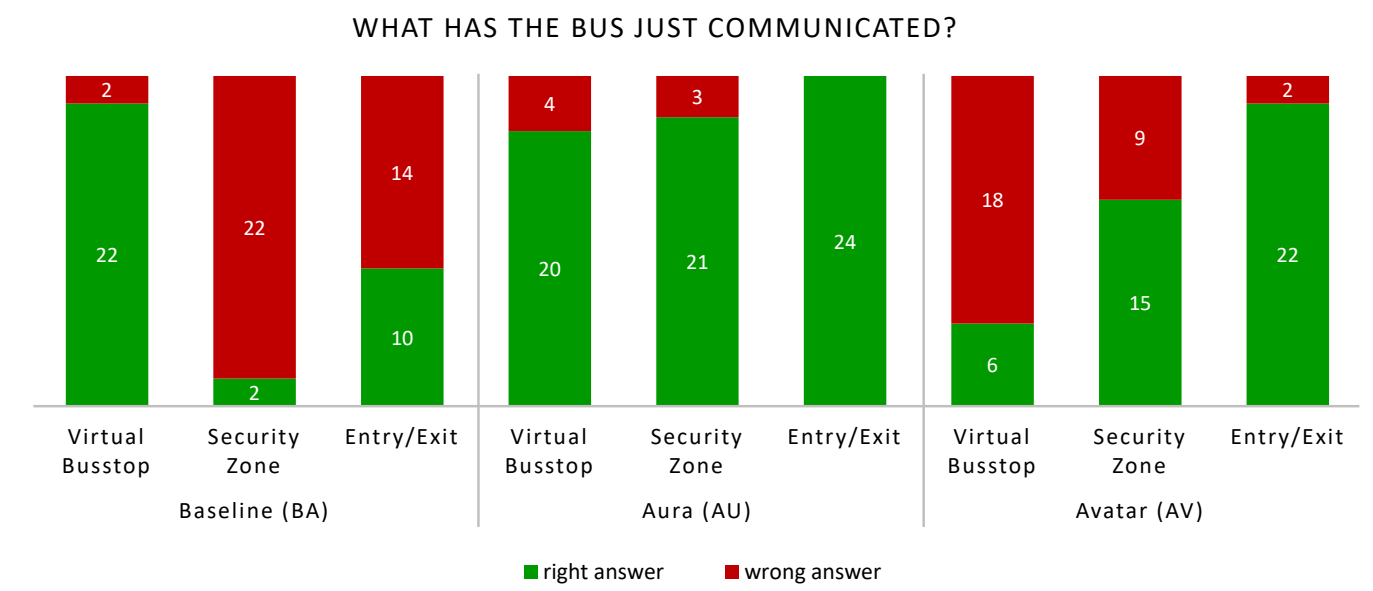

Figure 20. Results from counting the right and wrong answers from the question "What has the bus just communicated?" (Image source: own illustration).

In conclusion, the sum question confirms the tendencies towards aura that could already be observed in the previous ratings. AU achieved the highest mean score of 54.17, compared to BA (17.71) and AV (28.13) and was rated significantly better compared to BA $(p=0.000)$ as well as to AV $(p=0.015)$. There is no significant difference between the scores of $\mathrm{BA}$ and $\mathrm{AV}(p=0.582)$.

\subsubsection{Qualitative Results}

In the following, we give insights into the qualitative data from the semi-structured interviews. The baseline communication was overall perceived as comprehensible since it is well-known and conforms to conventional traffic regulations (14/24 mentions): "Very intuitive to understand. Same signals that you already know anyway." (Participant Exterior 10 ...PE10, AU-BA-AV) and "Clearly shows what the bus wants" (PE5, AV-BA-AU). Nevertheless, it was mentioned several times that the communication is not sufficient (5/24 mentions), often ambiguous (9/24 mentions) and too subtle (3/24 mentions): "Difficult to express different intentions, because it only flashes" (PE17, AV-BA-AU).

Many participants perceived communication with the aura concept as easy to understand (9/24 mentions). They liked that it was comprehensive, clear, and plain (10/24 mentions) but also highly noticeable from further away (5/24 mentions): "Striking, as whole bus lights up, but not unpleasantly intrusive" (PE10, AU-BA-AV). In particular, the colors red and green were rated positively since they are already known from traffic regulations, and therefore are intuitive and easy to understand (9/24 mentions): "Green lights immediately show: Everything is OK. Red immediately says: Stop, something is wrong" (PE17, AV-BA-AU). On the other hand, it was mentioned that the color codes are ambiguous or confusing sometimes (3/24 mentions): "Blue is not comprehensible and should not be used or reconsidered" (PE12, AV-AU-BA). Furthermore, some participants experienced the aura as impersonal and too technical (3/24 mentions): "You can see what the bus wants to say, but very technically solved" (PE6, AV-AU-BA). It was also stated that this kind of communication does not work for people with visual impairment (3/24 mentions).

Many participants experienced the communication with the avatar as human-like and easy (8/24 mentions). They stated, that "New technology combined with a familiar image of a bus driver conveys well-being and safety" (PE21, AU-AV-BA), which is in line with the pre-study finding (cf. Section 5.2.2: "the presence of the operator inspires trust"). In addition, several participants found it positive that the avatar addressed them personally $(7 / 24$ mentions) as it "gives the bus some personality and makes it not seem so cold" (PE11, AV-BA$\mathrm{AU})$. Others, in contrast, experienced the avatar as unfriendly and unattractive (6/24 mentions): "the fellow is totally patronized and unfriendly. This is rather old fashioned and not modern" (PE15, AU-AV-BA). Moreover, many participants experienced the communication as too complicated and not quickly graspable (9/24 mentions). One participant described 
the communication as "a typical innovation that only makes everything more complicated" (PE22, AU-BA-AV). Further concerns were expressed about the avatar not being gender neutral (1/24 mentions), not considering data privacy ( $1 / 24$ mentions) and misleading as it imitates a human being (1/24 mentions).

\subsection{Interior of the Automated Shuttle Bus}

The following section describes the most interesting qualitative and quantitative data excerpts that were gained from the data analysis.

\subsubsection{Quantitative Results}

For the evaluation of the quantitative data results, we counted the cards from the +3 years as well as the +25 years configurations and weighted them according to the following formula: cards with the prioritization one were weighted with 1 and cards with the prioritization two weighted with 0.5 . Afterwards, the cards of each sub-category were shown as a Top 3 list, in the form of side by side comparison configuration boards. Figure 21 present the comparison board of the most common feature cards of the +3 years and the +25 years concept.



Figure 21. Overview of the comparison configuration board for both time concepts (Image source: own illustration).

Another insight of the quantitative data we gained is the result of the sum question (distributing 100 points on the three categories). The average rating of these categories were 36 points for seats, 33 points for interior layout/appearance and 31 points for the information presentation-so no clear trend of importance is recognizable.

After completing each of the two concept configurations, participants were asked to fill-in the UEQ [70]. We then performed quantitative evaluation for the three dimensions of attractiveness, pragmatic, and hedonic quality (and further divided into sub scales attractiveness, perspicuity, efficiency, dependability, stimulation, and novelty). Figure 22 shows a comparison of the mean values of the three UEQ dimensions for the +3 years and +25 years concepts. Due to the kurtosis and skewness of the group indicating the values were normally distributed, we executed a paired two sampled $t$-Test at $\alpha=0.05$ for each of the three dimensions. The results show a significant difference $(p=0.00004)$ in the hedonic qualities between the +3 years and the +25 years conceptss, whereas the attractiveness and the pragmatic quality show no significant difference. A more detailed comparison of the resulting UEQ [70] scale means is shown in Figure 23. A paired two sampled $t$-Test at $\alpha=0.05$ was executed for the individual scales as well. Following the significance in the hedonic quality, the scales of stimulation $(p=0.00015)$ and novelty $(p=0.0006)$ also show a significant difference between the +3 years and the +25 years concepts. 
COMPARISON OF UEQ DIMENSIONS ATT, PQ AND HQ

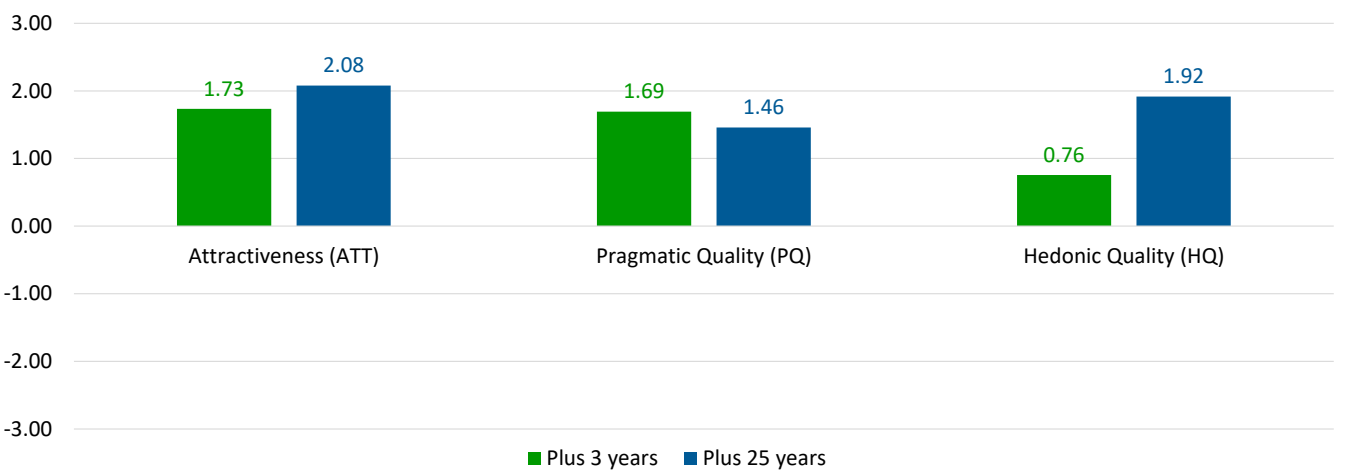

Figure 22. Results from the User Experience Questionnaire [70]: Attractiveness, Pragmatic, and Hedonic Quality (Image source: own illustration).

COMPARISON OF ALL SIX UEQ DIMENSIONS

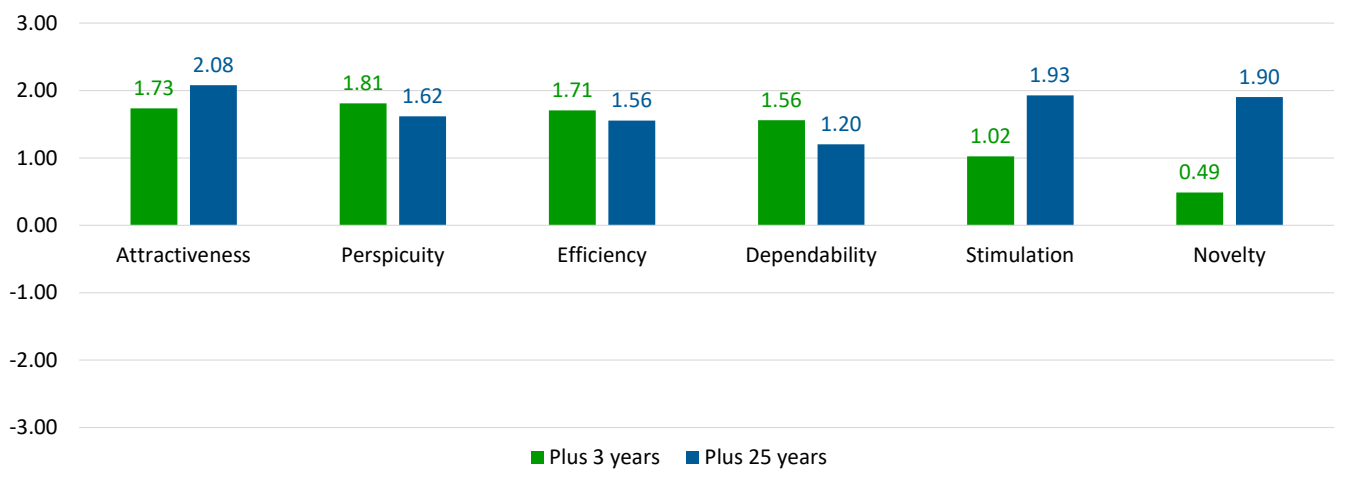

Figure 23. Results from the User Experience Questionnaire [70] with all individual dimensions (Image source: own illustration).

\subsubsection{Qualitative Results}

Using the methods of thinking aloud and semi-structured interviews, we could gather qualitative data to underpin the quantitative results. Qualitative data was collected and then inductively coded into the most commonly mentioned statements, which were included into the comparison boards next to the Top 3 cards of each time concept. For example, several participants mentioned that the round shaped seats appear most comfortable and pleasing for both time concepts (Participant Interior 8 ... PI8). Some participants mentioned for the +25 years configuration that the floating seats "are absolutely imaginable, futuristic and modern" (PI7). Furthermore, several participants can hardly imagine new inventions for the +3 years configuration, because it seems to be functionally /technically impossible (PI9). In contrast, some participants mentioned that the future (+25 years configuration) would be a really electronically focused world (PI3). The results are discussed in detail below.

\section{Discussion}

In the following, for the exterior, the results from Section 7 are placed in the context of the hypotheses, compared with results from related work, and discussed on a general level. For the interior design of automated shuttle buses (closer, further in the future), the results are first placed in the context of the hypotheses. Subsequently, design recommendations are derived from the results and discussed.

\subsection{Exterior of the Automated Shuttle Bus}

When looking at the overall influence of visual communication, the hypothesis $\mathbf{H}_{E .1}$ : Pedestrians give more positive overall UX ratings (indicated by the latent dimensions 
attractiveness, pragmatic quality, hedonic quality) in the variants AU and AV in contrast to BA can be accepted with one exception. While both concepts AV and AU were rated significantly better in the dimensions attractiveness and hedonic quality compared to BA, this was not the case for the comparison between AV and BA in terms of pragmatic quality. For the concept AU only, $\mathbf{H}_{E .1}$ can be accepted in all dimensions and also in terms of pragmatic quality. Like previous studies [37-39] showed, visual communication is valuable for other road users to convey a sense of security. However, unclear and complicated communication (like the humanized avatar concept) does not provide a better user experience, as expressed by one participant: "Too overloaded and confusing. The concept needs to be fundamentally rethought." (PE12, AV-AU-BA). Other qualitative data confirms that communication with the BA concept is not sufficient and often ambiguous (14/24 mentions).

Studying the individual situations by examining hypothesis $\mathbf{H}_{E .2}$ : Pedestrians give more positive ratings in the individual situations (indicated by the dimensions attractiveness, pragmatic quality, hedonic quality) in the variants AU and AV in contrast to BA has to be rejected, as it strongly depends on the situation and is not true for all situations (virtual bus stop, security zone and entry/exit process). The concepts AV and AU did not receive a more positive rating through all situations and dimensions compared to BA. Especially in the virtual bus stop situation, the ratings seem to show only little differences, as the baseline is described as "[...] comprehensible because it is well known, learnt and it conforms to conventional traffic regulations" (14/24 mentions). For the security zone situation, on the other hand, a difference can be estimated between AU and BA/AV. Presumably, the aura does particularly well in this key situation because it makes the sensor zone around the bus visible through light-an intuitive way of communication.

The hypothesis $\mathbf{H}_{E .3}$ : Pedestrians perceive the way of communication as more clear in the variants AU and AV in contrast to BA has to be rejected. Overall the AU concept achieved good results: more then 20/24 correct answers in each situation and 24/24 correct answers at the entry/exit process. The easy and established color-coding was well understood, which is in line with related work [34,37,39,41,42]. BA communication was often misinterpreted, especially in the security zone situation (22/24 mentions). However, the AV concept also gained a lot of false answers (18/24 mentions) at the virtual bus stop. We could assume that the AV concept is too ambiguous to understand-some participants remarked that the signals are not clear enough which confirms [38,39]. In general, people liked the human-like (8/24 mentions) and personal (7/24 mentions) interaction with the avatar, which is why we still see potential in the avatar concept.

In summary, concepts using anthropomorphic designs like eye contact or smiling on automated shuttle buses will lead to higher trust and confidence from other road users $[48,49]$, but apparently cannot eliminate wrong interpretations of the communication. The sum question confirms the tendencies towards the aura concept that could already be observed in the previous discussion. The AU concept performed best in almost all aspects (attractiveness, pragmatic and hedonic quality) compared to the other two concepts. People seem to prefer simple and highly visible light signals using already known color codes instead of complex humanized avatars, although both new concepts (AU and AV) are preferred in contrast to the baseline. This was also confirmed in the interviews, where the aura was described as easy to understand ( $9 / 24$ mentions), intuitive (9/24 mentions), and clear and plain (10/24 mentions).

Another interesting fact is that positive aspects were seen in all three concepts. This is a potential motivator to combine the tree concepts in some way. The BA communication should also be included in the AU and AV concepts ( $3 / 24$ mentions). To improve the whole communication between automated shuttle buses and other road users, some participants mentioned that all concepts could be improved through extensions such as auditory signals (speech/sounds), textual messages, or further colors. The AU concept should be extended with auditory signals (3/24 mentions) and text descriptions (2/24 mentions). For the AV 
concept participants thought about adding speech (4/24 mentions) and unmistakable text (3/24 mentions).

Nevertheless, not all people see the communication of automated shuttle buses as necessary. Especially in the entry/exit process some participants did not see the point, as they thought entry/exit practices had already been learned and were known to users.

\subsection{Interior of the Automated Shuttle Bus}

When considering the overall hedonic quality of both concept configurations, the hypothesis $\mathbf{H}_{I .1}$ : When envisioning the interior of an automated shuttle bus for the near future (+3 years), compared with the farther future (+25 years), potential users regard their hedonic quality with significant difference can be accepted. The individual hedonic dimensions, stimulation and novelty, of the +25 years concept were rated significantly better in comparison to the +3 years concept. Qualitative data confirm that users are open for completely new interior design approaches and are willing to trust new upcoming technologies (concept further in the future). Some participants envisioned the +25 years interior concept as more exciting, freaky, and with more functions (11/21 mentions) and that they want to enter a new world (9/21 mentions) in the further future.

Observing the overall pragmatic quality of both concepts by examining hypothesis $\mathbf{H}_{I .2}$ : When envisioning the interior of an automated shuttle bus for the near future (+3 years), compared with the farther future (+25 years), potential users regard their pragmatic quality with significant difference has to be rejected. The individual pragmatic dimensions perspicuity, efficiency, and dependability of both concepts were rated without a significant difference. The potential users rate these three dimensions equally important regardless of space of time.

Looking at the importance within the interior categories $\mathbf{H}_{I .3}$ : Potential passengers rate the importance of the three categories seating, interior design/appearance, and information presentation (including subcategories) significantly differently has to be rejected. The three different categories were rated without a significant difference and were equally important to the potential users.

Based on the results (Section 7.2), we further formulated design recommendations, separated into the categories of both concepts: closer in the future ( +3 years) and further in the future (+25 years). In total, 23 design recommendations were formulated. Nine of them are intended as recommendations applicable to both concepts, seven for the +3 years concept and another seven for the +25 years concept. Table 1 shows an overview of all design recommendations including information for which concept they are intended, the category from which they originated from, and a given number to differentiate them easily.

For a better understanding of how the recommendations emerged, particular recommendations of interest (highlighted in blue in Table 1) are revisited, discussed in detail, and supported with qualitative and quantitative results from the study evaluation. Selection of these aspects based on (a) frequency of mention and (b) relevance/importance of insight by (internal) majority voting.

All these design recommendations are not only limited to automated shuttle buses, but could also be (partly) implemented today and improve the user experience in manually operated buses. 
Table 1. Overview of the derived recommendations for the interior design of automated shuttle buses, separated according to the categories both concepts, closer in the future (+3 years), and further in the future (+25 years) (Image source: own illustration).

\begin{tabular}{|c|c|c|c|}
\hline For which Concept & Category & Recommendation & No. \\
\hline Both concepts & Seats/Shape & $\begin{array}{l}\text { Regarding the shape of the seats in the interior it is recommended } \\
\text { to consider rounded and edged shapes. }\end{array}$ & 1 \\
\hline Both concepts & Seats/Arrangement/Body Position & $\begin{array}{l}\text { Regarding the interior it is recommended to allow } \\
\text { standing/leaning in the bus and integrate special leaning spaces } \\
\text { for short distance travelers. }\end{array}$ & 2 \\
\hline Both concepts & Seats/Arrangement/Seat Placement & $\begin{array}{l}\text { Regarding the placement of the seats in the interior it is } \\
\text { recommended to consider single positioned seats with enough } \\
\text { distance to other seating possibilities. }\end{array}$ & 3 \\
\hline Both concepts & Seats/Arrangement/Seating Direction & $\begin{array}{l}\text { Regarding the seating direction in the interior it is recommended } \\
\text { to consider sideways placed seats instead of backwards } \\
\text { placed seats. }\end{array}$ & 4 \\
\hline Both concepts & Seats/Functionality & $\begin{array}{l}\text { Regarding the seat functionality of the interior it is recommended } \\
\text { to consider interactive seats. }\end{array}$ & 5 \\
\hline Both concepts & Interior Layout/Areas & $\begin{array}{l}\text { Regarding the interior layout it is recommended to consider both } \\
\text { private areas, as well as restricted social areas in the bus interior. }\end{array}$ & 6 \\
\hline Both concepts & Interior Layout/Design & $\begin{array}{l}\text { Regarding the interior design language it is recommended to } \\
\text { consider bright, and warm colors as well as natural materials. An } \\
\text { inspiration could be a combination of the modern and mystic } \\
\text { design language. }\end{array}$ & 7 \\
\hline Both concepts & Information Presentation/Visual Senses & $\begin{array}{l}\text { Regarding the visual information presentation in the interior it is } \\
\text { recommended to provide the passengers with public distributed } \\
\text { information via a window display. }\end{array}$ & 8 \\
\hline Both concepts & Information Presentation/Other Senses & $\begin{array}{l}\text { Regarding the general information presentation in the interior it is } \\
\text { recommended to consider audio announcements via integrated } \\
\text { loudspeakers, which could be combined with subtle vibrations. }\end{array}$ & 9 \\
\hline Concept +3 years & Seats/Arrangement/Body Position & $\begin{array}{l}\text { Regarding the body position it is recommended to consider } \\
\text { upright sitting for a shuttle bus concept in }+3 \text { years. }\end{array}$ & 10 \\
\hline Concept +3 years & Seats/Arrangement/Seat Placement & $\begin{array}{l}\text { Regarding the placement of the seats in the interior it is } \\
\text { recommended to consider integrating some flexible seats for a } \\
\text { shuttle bus concept in }+3 \text { years. }\end{array}$ & 11 \\
\hline Concept +3 years & Seats/Arrangement/Seating Direction & $\begin{array}{l}\text { Regarding the seat direction it is recommended to install most of } \\
\text { the seats into driving direction for a shuttle bus concept in } \\
+3 \text { years. }\end{array}$ & 12 \\
\hline Concept +3 years & Seats/Functionalities & $\begin{array}{l}\text { Regarding the seat functionalities it is recommended to consider } \\
\text { integrating adjustable seats for a shuttle bus in }+3 \text { years. }\end{array}$ & 13 \\
\hline Concept +3 years & Interior Layout \& Appearance/Interior Areas & $\begin{array}{l}\text { Regarding the interior areas it is recommended to consider more } \\
\text { open and social spaces in the shuttle bus concept for }+3 \text { years. }\end{array}$ & 14 \\
\hline Concept +3 years & $\begin{array}{l}\text { Interior Layout \& Appearance/Design } \\
\text { Language }\end{array}$ & $\begin{array}{l}\text { Regarding the interior design language it is recommended to } \\
\text { consider a minimalistic and functional design. }\end{array}$ & 15 \\
\hline Concept +3 years & Information Presentation/Visual Senses & $\begin{array}{l}\text { For visualizing private/on demand information it is } \\
\text { recommended to consider using holograms and avatars for a } \\
\text { shuttle bus in }+25 \text { years. }\end{array}$ & 16 \\
\hline Concept +25 years & Seats/Arrangement/Body Position & $\begin{array}{l}\text { Regarding the body position it is recommended to consider seats } \\
\text { that allow laid back sitting and lying for a shuttle bus concept in } \\
+25 \text { years. }\end{array}$ & 17 \\
\hline Concept +25 years & Seats/Arrangement/Seat Placement & $\begin{array}{l}\text { Regarding the seating placements it is recommended to think } \\
\text { about completely new ways of seating that may inherent free } \\
\text { placement or stacking. }\end{array}$ & 18 \\
\hline Concept +25 years & Seats/Arrangement/Seating Direction & $\begin{array}{l}\text { Regarding the seat direction it is recommended to consider } \\
\text { rotatable seats, that allow a changing the seating direction in the } \\
+25 \text { concept. }\end{array}$ & 19 \\
\hline Concept +25 years & Seats/Functionality & $\begin{array}{l}\text { Regarding the seat functionality of the }+25 \text { years concept it is } \\
\text { recommended to think about completely new functionalities that } \\
\text { may include sleeping and energizing. }\end{array}$ & 20 \\
\hline Concept +25 years & Interior Layout \& Appearance/Interior Areas & $\begin{array}{l}\text { Regarding the interior areas it is recommended to consider more } \\
\text { private areas in the shuttle bus concept for }+25 \text { years. }\end{array}$ & 21 \\
\hline Concept +25 years & Information Presentation/Visual Senses & $\begin{array}{l}\text { For visualizing private/on demand information it is } \\
\text { recommended to consider using holograms and avatars for a } \\
\text { shuttle bus in }+25 \text { years. }\end{array}$ & 22 \\
\hline Concept +25 years & Information Presentation/Other Senses & $\begin{array}{l}\text { Regarding the information presentation in the interior of the } \\
\text { future, it is recommended to step out of the box and introduce } \\
\text { completely new ways of presenting information. }\end{array}$ & 23 \\
\hline
\end{tabular}




\subsubsection{Selected Design Recommendations Applicable to Both Concepts}

Recommendation \#3 has emerged from the categories of seats and seat placement. It follows the assertion that the participants prefer single seating possibilities in both concepts. This statement is supported by qualitative data of the interviews where participants said that they prefer privacy when traveling alone (PI9) and the positioning of the seats should provide enough distance to others (PI8). Therefore single positioned seats with enough distance to other seating possibilities are recommended.

Recommendation \#8 from the category information presentation/visual senses claims that participants favor window displays for the public information presentation. According to the answers of participants, window displays are considered as a "cool and futuristic" idea (PI5) where information can easily and comfortably be watched while looking outside of the window (PI5). The UEQ [70] underlines this with the importance of novelty and stimulation. Therefore, the recommendation is to provide the passengers with publicly distributed information via a window display.

\subsubsection{Selected Design Recommendations for Closer in the Future ( +3 Years)}

Recommendation \#14 in the category interior layout/appearance and the subcategory interior areas has emerged from the statement that the participants tend to prefer more open and social spaces in the +3 years concept. This is underpinned by qualitative data in which bright, natural light is preferred, in addition to making the nature outside more visual in the bus with the open area concept (PI6). Participants like to have the opportunity to communicate and hang out with friends (PI3). In addition, isolated booths (Séparées) can be used for meetings and travelers who do not want to be disturbed (PI5). The UEQ [70] supports this statement with efficiency and perspicuity which can be seen in open areas and isolated booths. This is why the use of more open and social spaces in the shuttle bus concept for +3 years is suggested.

In the same main category, but in subcategory design language, Recommendation \#15 appears. The participants have a preference for minimalist and functional design language. This suggestion was drawn from qualitative data where the users said that the focus for a short journey is on functionality (PI5), and that a minimalist design is is perceived as sufficient for public transportation (PI3). The UEQ [70] supports this by the efficiency which can be seen in a minimalist approach. Therefore, regarding the interior design language it is recommended to consider a minimalist and functional design.

\subsubsection{Selected Design Recommendations for Further in the Future (+25 years)}

Regarding the category body position in seats/arrangement, the participants imagine the +25 years body position as more laid back and relaxed. This statement was supported by qualitative data where the users said that the lying position should help to relax more and it provides the necessary comfort (PI15). Furthermore, participants want to have both options laid back sitting and lying body positions in one seat (PI4). The UEQ [70] underlines this with novelty in terms of lying seats in the future concept. The resulting recommendation \#17 is to consider seats that allow laid back sitting and lying for a shuttle bus concept in +25 years.

Recommendation \#20 is part of the functionality subcategory. The resulting statement from the qualitative and UEQ [70] data is that participants are open to completely new types of functions for their seats, such as a power-nap function (via "cryosleep", a technology to lower person's body temperature, causing them to slip into a sort of hibernation [73]) or "energizing". Some people like to sleep in public transportation anyway (PI4), so cryosleeping is perceived as convenient for them. Energizing, i.e., "filling up the batteries", is also seen as highly desirable in the future (PI2). Novelty and stimulation, as measured by the UEQ, Ref. [70] are seen in the new functionalities that are used while on the bus. Therefore, the recommendation is to think about completely new functionality for the seats in future automated shuttle buses, which can include sleeping and energizing. 


\subsubsection{Summary}

Our results confirm that, on the one hand, users are open to and trust new technologies, but on the other hand, they are also afraid of a lack of privacy and insufficient data security with advanced technologies. Brain-computer interfaces, for example, that are aimed at offering convenient ways to control future interfaces appear insecure to users, because they assume that this type of interface connects directly to their brain activity and would therefore have the power to read private thoughts (privacy violation). Most people want individual seating and the ability to have enough space between themselves and others. This corresponds to the known behavior that in public transport everyone wants to have a row of seats alone. Passengers often physically defend their seat by placing an object, such as a bag, on the adjacent seat or spreading out to take up more than half of a pair of seats [74] (p. 21). Another explanation could be the COVID-19 pandemic prevalent at the time of the study, which resulted in a general increased distancing awareness. This behavior was further confirmed by Schuß et al. [75], stating that shared autonomous vehicles (SAVs) should provide passengers with options to reserve multiple (adjacent) seats already before the journey. With the approach of letting the users configure their own shuttle bus, they were totally free in their choices and only limited by the cards as options. This offers insights of the unfiltered truth of their thoughts. The design recommendations are based on this outcome and therefore describe the direct needs and wants of the users. These recommendations give guidance for future design decisions and can spark new ideas regarding the conception of a near or far future automated shuttle bus interior. The recommendations can act as a first step to support finding solutions that improve the overall user experience of the shuttle bus. Regarding this fact, the different time concepts help to improve the user experience in a long term view and show possibilities for using advanced technologies.

\section{Conclusions}

For public transport operators, the deployment of automated shuttle buses as an additional mode of transportation (on the outskirts of town or in less populated areas) is an important building block for future mobility and a precondition for a self-determined and individual lifestyle for potential users facing economic, ecological, and social challenges. With this work, we contribute to the successful establishment of automated shuttle buses in public transport with broad acceptance among the population. We explored how to improve the user experience when interacting with automated shuttle buses, both in the exterior and in the interior. By applying the user-centered design process we were able to develop different concepts in an iterative way. For exterior communication, we evaluated two communication concepts against each other and against the baseline in a study with $n=24$ participants. For interior design, we investigated different aspects such as seats, general layout/visual appearance, or information presentation in online sessions with $n=21$ participants. From the study results we were able to derive and present design recommendations. In a nutshell, our main findings are:

- Subtle exterior communication using established color codes seems to outperform direct communication using anthropomorphic designs (human looking avatar); both concepts outperform current solutions (baseline).

- To improve communication ability, visual signals should be combined with auditory (speech, sounds) and textual messages.

- Not all road users are enthusiastic about automated shuttle bus communication in public spaces-many do not see the purpose of it (yet).

- Most people envision the interior of an (automated) shuttle bus in the closer future (+3 years) as minimalist, but simple and functional. The interior design further in the future ( +25 years) should offer a greater degree of comfort, functionality and technology.

- $\quad$ People are open for completely new interior design approaches and are willing to trust new upcoming technologies. 
- The most important needs in an (automated) shuttle bus are personal space and privacy.

\section{Limitations and Future Work}

Certain limitations for both the exterior as well as the interior evolved over the course of this project. Primarily, due to the ongoing COVID-19 pandemic, the studies described in this article are more theoretical in nature for both exterior and interior concepts-only parts of the investigations could be conducted in and around an operating automated shuttle bus and in the field; nevertheless, most studies could be conducted using at least face-to-face online meetings rather than an online-only questionnaire basis. As a future outlook, the concepts should be implemented in a tangible way and further be tested (as planned) in a real automated shuttle bus and under natural conditions. Another limitation of this project is that the concepts for interior and exterior have been considered in relative isolation. In chapter 8 , we have tried to derive overarching recommendations-but there is still no overall concept of how interior and exterior should be aligned with each other. Combining both exterior and interior results into one self-contained demonstration would be desirable in order to get more holistic feedback in future studies. The whole spectrum of the project is complex, multi-layered, and has many dimensions that could be considered. In this work, we wanted to look at the most relevant aspects and address the main target groups on the one hand, but not exclude marginalized groups on the other. Due to limited resources, only some variants focusing on visual and auditory communication could be investigated. This is another limitation of the work. (However, the selection of the same was not arbitrary, but based on group discussions and majority decisions).

Author Contributions: Conceptualization, A.R., D.S. and J.H.; methodology, all authors; validationteam exterior, D.S., B.H., M.K., E.P. and S.S.; validation-team interior: J.H., I.K., J.M., A.M., G.S., D.B. and E.A., writing—original draft preparation, all authors; writing-review and editing, A.R., D.S. and J.M.; supervision, A.R., project administration, A.R.; funding acquisition, A.R. All authors have read and agreed to the published version of the manuscript.

Funding: This work was carried out as a project within the master's program User Experience Design at Technische Hochschule Ingolstadt and financed by study grants from the faculty of computer science.

Institutional Review Board Statement: Participation was in accordance with the ethical guidelines stated in the Declaration of Helsinki [76]: participation was voluntary, participants were obliged to provide their written informed consent, and had the opportunity to abort the study at any time and leave comments or feedback. Study participants were not exposed to any kind of physical or psychological harm during the study; therefore, based on our university's regulations, ethical approval was not required.

Informed Consent Statement: Informed consent was obtained from all subjects prior to the beginning of the study.

Data Availability Statement: The data presented in this study are available on request from the corresponding author.

Acknowledgments: We applied the SDC approach for the sequence of authors. We thank DB Regio, in particular Christian Neff and Stefan Kretzschmar, for the pleasant and constant support and constructive feedback throughout this project. We further thank Caroline Kendrick and Megan Smith for their support in finalizing the manuscript.

Conflicts of Interest: The authors declare no conflict of interest.

\section{References}

1. Maurer, M.; Gerdes, J.; Lenz, B.; Winner, H. Autonomes Fahren: Technische, Rechtliche und Gesellschaftliche Aspekte; Springer: Berlin/Heidelberg, Germany, 2015.

2. Riener, A.; Appel, A.; Dorner, W.; Huber, T.; Kolb, J.C.; Wagner, H. Autonome Shuttlebusse im ÖPNV: Analysen und Bewertungen zum Fallbeispiel Bad Birnbach aus Technischer, Gesellschaftlicher und Planerischer Sicht; Springer Nature: Berlin/Heidelberg, Germany, 2020. 
3. Braun, M.; Gudd, C.; Rohs, M.; Seyfferth, J.; Teichmann, G. Autonome Busse im ÖPNV. Innovativ, Nachhaltig-Aber Auch Finanzierbar? A PricewaterhouseCoopers (PWC) Report; PWC: Frankfurt am Main, Germany, 2020.

4. Müller, M.; Müller, T.; Talkhestani, B.A.; Marks, P.; Jazdi, N.; Weyrich, M. Industrial autonomous systems: A survey on definitions, characteristics and abilities. Automatic 2021, 69, 3-13. [CrossRef]

5. Bucchiarone, A.; Battisti, S.; Marconi, A.; Maldacea, R.; Ponce, D. Autonomous Shuttle-as-a-Service (ASaaS): Challenges, Opportunities, and Social Implications. TechRxiv 2020, 6-12. [CrossRef]

6. Frison, A.K.; Wintersberger, P.; Riener, A. First Person Trolley Problem: Evaluation of Drivers' Ethical Decisions in a Driving Simulator. In Proceedings of the AutomotiveUI '16 Adjunct: Adjunct Proceedings of the 8th International Conference on Automotive User Interfaces and Interactive Vehicular Applications, Ann Arbor, MI, USA, 24-26 October 2016. [CrossRef]

7. Bonnefon, J.F.; Shariff, A.; Rahwan, I. The social dilemma of autonomous vehicles. Science 2016, 352, 1573-1576. [CrossRef]

8. Frison, A.K.; Wintersberger, P.; Liu, T.; Riener, A. Why do you like to drive automated?: A context-dependent analysis of highly automated driving to elaborate requirements for intelligent user interfaces. In Proceedings of the 24th International Conference on Intelligent User Interfaces, Marina del Ray, CA, USA, 17-20 March 2019; pp. 528-537. [CrossRef]

9. Mirnig, A.G.; Gärtner, M.; Füssl, E.; Ausserer, K.; Meschtscherjakov, A.; Wallner, V.; Kubesch, M.; Tscheligi, M. Suppose your bus broke down and nobody came. Pers. Ubiquitous Comput. 2020, 24, 797-812. [CrossRef]

10. Milakis, D.; Van Arem, B.; Van Wee, B. Policy and society related implications of automated driving: A review of literature and directions for future research. J. Intell. Transp. Syst. 2017, 21, 324-348. [CrossRef]

11. Kyriakidis, M.; Happee, R.; de Winter, J.C. Public opinion on automated driving: Results of an international questionnaire among 5000 respondents. Transp. Res. Part F Traffic Psychol. Behav. 2015, 32, 127-140. [CrossRef]

12. Hohm, A.; Lotz, F.; Fochler, O.; Lueke, S.; Winner, H. Automated Driving in Real Traffic: From Current Technical Approaches towards Architectural Perspectives; Technical Report, SAE Technical Paper; SAE International: Warrendale, PA, USA, 2014.

13. Klomp, M.; Jonasson, M.; Laine, L.; Henderson, L.; Regolin, E.; Schumi, S. Trends in vehicle motion control for automated driving on public roads. Veh. Syst. Dyn. 2019, 57, 1028-1061. [CrossRef]

14. Schaarschmidt, E.; Yen, R.; Bosch, R.; Zwicker, L.; Schade, J.; Petzoldt, T. Grundlagen zur Kommunikation Zwischen Automatisierten Kraftfahrzeugen und Verkehrsteilnehmern; Bundesanstalt für Straßenwesen (BASt): Bergisch Gladbach, Germany, 2021.

15. Grahn, H.; Kujala, T.; Silvennoinen, J.; Leppänen, A.; Saariluoma, P. Expert Drivers' Prospective Thinking-Aloud to Enhance Automated Driving Technologies-Investigating Uncertainty and Anticipation in Traffic. Accid. Anal. Prev. 2020, $146,105717$. [CrossRef] [PubMed]

16. Diels, C.; Erol, T.; Kukova, M.; Wasser, J.; Cieslak, M.; Payre, W.; Miglani, A.; Mansfield, N.; Hodder, S.; Bos, J. Designing for Comfort in Shared and Automated Vehicles (SAV): A Conceptual Framework. In Proceedings of the International Comfort Congress, ICC2017, San Diego, CA, USA, 7 June 2017.

17. Ainsalu, J.; Arffman, V.; Bellone, M.; Ellner, M.; Haapamäki, T.; Haavisto, N.; Josefson, E.; Ismailogullari, A.; Lee, B.; Madland, O.; et al. State of the art of automated buses. Sustainability 2018, 10, 3118.

18. Beckmann, S.; Biletska, O.; Zadek, H. Requirements for Pilot Routes and Infrastructure for the Introduction of Automated Shuttle Buses in Public Areas. Logist. J. Proc. 2020, 2020. [CrossRef]

19. Zhu, L.; Wang, J.; Garikapati, V.; Young, S. Decision support tool for planning neighborhood-scale deployment of low-speed shared automated shuttles. Transp. Res. Rec. 2020, 2674, 1-14. [CrossRef]

20. Cao, Z.; Ceder, A.A. Autonomous shuttle bus service timetabling and vehicle scheduling using skip-stop tactic. Transp. Res. Part C Emerg. Technol. 2019, 102, 370-395. [CrossRef]

21. Zellner, M.; Massey, D.; Shiftan, Y.; Levine, J.; Arquero, M. Overcoming the last-mile problem with transportation and land-use improvements: An agent-based approach. Int. J. Transp. 2016, 4, 1-26. [CrossRef]

22. Salonen, A.O. Passenger's subjective traffic safety, in-vehicle security and emergency management in the driverless shuttle bus in Finland. Transp. Policy 2018, 61, 106-110. [CrossRef]

23. Tirachini, A.; Antoniou, C. The economics of automated public transport: Effects on operator cost, travel time, fare and subsidy. Econ. Transp. 2020, 21, 100151. [CrossRef]

24. Amini, R.E.; Katrakazas, C.; Riener, A.; Antoniou, C. Interaction of automated driving systems with pedestrians: Challenges, current solutions, and recommendations for eHMIs. Transp. Rev. 2021, 1-26. [CrossRef]

25. Dey, D.; Habibovic, A.; Pfleging, B.; Martens, M.; Terken, J. Color and Animation Preferences for a Light Band EHMI in Interactions Between Automated Vehicles and Pedestrians. In Proceedings of the 2020 CHI Conference on Human Factors in Computing Systems, Honolulu, HI, USA, 25-30 April 2020; Association for Computing Machinery: New York, NY, USA, 2020; pp. 1-13. [CrossRef]

26. Dey, D.; Habibovic, A.; Löcken, A.; Wintersberger, P.; Pfleging, B.; Riener, A.; Martens, M.; Terken, J. Taming the eHMI jungle: A classification taxonomy to guide, compare, and assess the design principles of automated vehicles' external human-machine interfaces. Transp. Res. Interdiscip. Perspect. 2020, 7, 100174. [CrossRef]

27. Mirnig, A.G.; Wallner, V.; Gärtner, M.; Meschtscherjakov, A.; Tscheligi, M. Capacity Management in an Automated Shuttle Bus: Findings from a Lab Study. In Proceedings of the 12th International Conference on Automotive User Interfaces and Interactive Vehicular Applications, Online, 21-29 September 2020; Association for Computing Machinery: New York, NY, USA, 2020; pp. 270-279. [CrossRef] 
28. Lundgren, V.M.; Habibovic, A.; Andersson, J.; Lagström, T.; Nilsson, M.; Sirkka, A.; Fagerlönn, J.; Fredriksson, R.; Edgren, C.; Krupenia, S.; et al. Will there be new communication needs when introducing automated vehicles to the urban context? In Advances in Human Aspects of Transportation; Springer: Berlin/Heidelberg, Germany, 2017; pp. 485-497.

29. Färber, B. Kommunikationsprobleme zwischen autonomen Fahrzeugen und menschlichen Fahrern. In Autonomes Fahren; Springer: Berlin/Heidelberg, Germany, 2015; pp. 127-146.

30. Schieben, A.; Wilbrink, M.; Kettwich, C.; Madigan, R.; Louw, T.; Merat, N. Designing the interaction of automated vehicles with other traffic participants: Design considerations based on human needs and expectations. Cogn. Technol. Work 2019, 21, 69-85. [CrossRef]

31. Lagström, T.; Malmsten Lundgren, V. AVIP-Autonomous Vehicles' Interaction with Pedestrians-An Investigation of PedestrianDriver Communication and Development of a Vehicle External Interface. Master's Thesis, Chalmers University of Technology, Gothenborg, Sweden, 2016.

32. Palmeiro, A.R.; van der Kint, S.; Vissers, L.; Farah, H.; de Winter, J.C.; Hagenzieker, M. Interaction between pedestrians and automated vehicles: A Wizard of Oz experiment. Transp. Res. Part F Traffic Psychol. Behav. 2018, 58, 1005-1020. [CrossRef]

33. Rouchitsas, A.; Alm, H. External human-machine interfaces for autonomous vehicle-to-pedestrian communication: A review of empirical work. Front. Psychol. 2019, 10, 2757. [CrossRef]

34. Löcken, A.; Wintersberger, P.; Frison, A.K.; Riener, A. Investigating user requirements for communication between automated vehicles and vulnerable road users. In Proceedings of the 2019 IEEE Intelligent Vehicles Symposium (IV), Paris, France, 9-12 June 2019; pp. 879-884.

35. Ackermann, C.; Beggiato, M.; Schubert, S.; Krems, J.F. An experimental study to investigate design and assessment criteria: What is important for communication between pedestrians and automated vehicles? Appl. Ergon. 2019, 75, 272-282. [CrossRef] [PubMed]

36. Clamann, M.; Aubert, M.; Cummings, M.L. Evaluation of Vehicle-to-Pedestrian Communication Displays for Autonomous Vehicles; Technical Report; Transportation Research Board: Washington, DC, USA, 2017.

37. Holländer, K.; Colley, A.; Mai, C.; Häkkilä, J.; Alt, F.; Pfleging, B. Investigating the influence of external car displays on pedestrians' crossing behavior in virtual reality. In Proceedings of the 21st International Conference on Human-Computer Interaction with Mobile Devices and Services, Taipei, Taiwan, 1-4 October 2019; pp. 1-11.

38. Mahadevan, K.; Somanath, S.; Sharlin, E. Communicating awareness and intent in autonomous vehicle-pedestrian interaction. In Proceedings of the 2018 CHI Conference on Human Factors in Computing Systems, Montreal, QC, Canada, 26-31 April 2018; pp. 1-12.

39. Löcken, A.; Golling, C.; Riener, A. How Should Automated Vehicles Interact with Pedestrians? A Comparative Analysis of Interaction Concepts in Virtual Reality; Association for Computing Machinery: New York, NY, USA, 2019; pp. 262-274. [CrossRef]

40. Footage Audi Aicon. 2017. Available online: https://www.audi-mediacenter.com/de/audimediatv/video/footage-audi-aicon3789 (accessed on 29 July 2021).

41. Philipp Wintersberger, A.R. Chapter In-situ Analysis of Behavior Patterns and User Experience of Automated Shuttle Bus Users. In User Experience Design in the Era of Automated Driving; Studies in Computational Intelligence; Springer: Berlin/Heidelberg, Germany, 2021; p. 29.

42. Zhang, J.; Vinkhuyzen, E.; Cefkin, M. Evaluation of an autonomous vehicle external communication system concept: A survey study. In International Conference on Applied Human Factors and Ergonomics; Springer: Berlin/Heidelberg, Germany, 2017; pp. 650-661.

43. The Mercedes-Benz Future Bus. 2016. Available online: https://www.daimler.com/innovation/autonomous-driving/future-bus. html (accessed on 29 July 2021).

44. Chang, C.M.; Toda, K.; Sakamoto, D.; Igarashi, T. Eyes on a Car: An Interface Design for Communication between an Autonomous Car and a Pedestrian. In Proceedings of the 9th International Conference on Automotive User Interfaces and Interactive Vehicular Applications, Oldenburg, Germany, 24-27 September 2017; pp. 65-73.

45. Hutson, M. A Matter of Trust. Science 2017, 358, 1375-1377. [CrossRef]

46. Walters, M.L.; Syrdal, D.S.; Dautenhahn, K.; Te Boekhorst, R.; Koay, K.L. Avoiding the uncanny valley: Robot appearance, personality and consistency of behavior in an attention-seeking home scenario for a robot companion. Auton. Robot. 2008, 24, 159-178. [CrossRef]

47. Jaguar Land Rover's Prototype Driverless Car Makes Eye Contact with Pedestrians. 2018. Available online: https://www. dezeen.com/2018/09/04/jaguar-land-rovers-prototype-driverless-car-makes-eye-contact-pedestrians-transport/ (accessed on 29 July 2021).

48. Specially-Designed Toyota-Tokyo 2020 Version- e-Palette to Provide Automated Mobility to Athletes. 2019. Available online: https:/ / global.toyota/en/newsroom/corporate/29933371.html (accessed on 29 July 2021).

49. Self Driving Car That Sees You. The Smiling Car. 2020. Available online: https://semcon.com/smilingcar/ (accessed on 29 July 2021).

50. Lundquist, M. Autonomous Bus Passenger Experience. 2018. Available online: http://urn.kb.se/resolve?urn=urn:nbn:se:umu: diva-149064 (accessed on 29 July 2021).

51. Vesa, H. Design of an Autonomous Shuttle Bus Interior and Service. 2020. Available online: https://medium.com/fortumdesign/design-of-an-autonomous-shuttle-bus-interior-and-service-d9fcfd8ab927 (accessed on 29 July 2021). 
52. Forrest, C. Could the Autonomous Mercedes Future Bus Lead to Driverless Public Transportation? 2016. Available online: https: / / www.techrepublic.com/article/could-the-autonomous-mercedes-future-bus-lead-to-driverless-public-transportation/ (accessed on 29 July 2021).

53. Moser, C. User Experience Design. Mit erlebniszentrierter Softwareentwicklung zu Produkten, die Begeistern; Springer: Berlin/Heidelberg, Germany, 2012.

54. Gacha Autonomous Shuttle Bus. 2019. Available online: https://www.forbes.com/sites/nargessbanks/2019/03/15/muji-gachaelectric-autonomous-bus/?sh=1329e28ea010 (accessed on 29 July 2021).

55. Köhler, A.L.; Prinz, F.; Wang, L.; Becker, J.; Voß, G.M.I.; Ladwig, S.; Eckstein, L.; Schulte, T.; Depner, N. How will we travel autonomously? User needs for interior concepts and requirements towards occupant safety. In Proceedings of the 28th Aachen Colloquium Automobile and Engine Technology, Aachen, Germany, 8 October 2019.

56. EZ10 Passenger Shuttle. Available online: https://easymile.com/vehicle-solutions/ez10-passenger-shuttle (accessed on 29 July 2021).

57. Barkow, B. Industry Perspectives on Interior Bus Design Issues: Background Research on Current Practice and Issues; Canadian Urban Transit Association: Toronto, ON, Canada, 1992.

58. Hwangbo, H.; Kim, J.; Kim, S.; Ji, Y.G. Toward Universal Design in Public Transportation Systems: An Analysis of Low-Floor Bus Passenger Behavior with Video Observations. Hum. Factors Ergon. Manuf. Serv. Ind. 2015, 25, 183-197. [CrossRef]

59. Yang, Y.; Fleischer, M.; Bengler, K. Chicken or Egg Problem? New Challenges and Proposals of Digital Human Modeling and Interior Development of Automated Vehicles. In Advances in Additive Manufacturing, Modeling Systems and 3D Prototyping; Di Nicolantonio, M., Rossi, E., Alexander, T., Eds.; Springer International Publishing: Cham, Switzerland, 2020 ; pp. $453-463$.

60. ISO 9241-210:2019 Ergonomie der Mensch-System-Interaktion: Teil 210: Prozess zur Gestaltung Gebrauchstauglicher Interaktiver Systeme (ISO 9241-210:2019): Ausgabe: 2019-04-01; Deutsche Fassung EN ISO 9241-210:2019; Deutsche Fassung, DIN Deutsches Institut für Normung: Berlin, Germany, 2019.

61. Pettersson, I.; Lachner, F.; Frison, A.K.; Riener, A.; Butz, A. A Bermuda Triangle? A Review of Method Application and Triangulation in User Experience Evaluation. In Proceedings of the $2018 \mathrm{CHI}$ Conference on Human Factors in Computing Systems, Montreal, QC, Canada, 21-26 April 2018; Association for Computing Machinery: New York, NY, USA, 2018; pp. 1-16. [CrossRef]

62. Winkler, N.; Roethke, K.; Siegfried, N.; Benlian, A. Lose Yourself in VR: Exploring the Effects of Virtual Reality on Individuals' Immersion. In Proceedings of the 53rd Hawaii International Conference on System Sciences, HICSS 2020, Maui, HI, USA, 7-10 January 2020; pp. 1-10.

63. Iskander, J.; Attia, M.; Saleh, K.; Nahavandi, D.; Abobakr, A.; Mohamed, S.; Asadi, H.; Khosravi, A.; Lim, C.P.; Hossny, M. From car sickness to autonomous car sickness: A review. Transp. Res. Part F Traffic Psychol. Behav. 2019, 62, 716-726. [CrossRef]

64. Chang, H.M.; Díaz, M.; Català, A.; Chen, W.; Rauterberg, M. Mood Boards as a Universal Tool for Investigating Emotional Experience. In Design, User Experience, and Usability. User Experience Design Practice; Marcus, A., Ed.; Springer International Publishing: Cham, Switzerland, 2014; pp. 220-231.

65. Cassidy, T. The Mood Board Process Modeled and Understood as a Qualitative Design Research Tool. Fash. Pract. 2011, 3, $225-251$. [CrossRef]

66. IBM Corp. IBM SPSS Statistics for Windows; Version 24.0; IBM Corp.: Armonk, NY, USA, 2015.

67. GmbH. LimeSurvey: An Open Source Survey Tool. 2021. Available online: https://www.limesurvey.org/ (accessed on 29 July 2021).

68. Hassenzahl, M. The hedonic/pragmatic model of user experience. In Towards A UX Manifacture; 2007; Volume 10. Available online: http:/ / www.cost294.org (accessed on 29 July 2021).

69. AttrakDiff. 2021. Available online: http:/ / www.attrakdiff.de/ (accessed on 29 July 2021).

70. Schrepp, M. UEQ User Experience Questionnaire. 2021. Available online: https:/ / www.ueq-online.org/ (accessed on 29 July 2021).

71. Rammstedt, B.; John, O.P. Measuring personality in one minute or less: A 10-item short version of the Big Five Inventory in English and German. J. Res. Personal. 2007, 41, 203-212. [CrossRef]

72. Miro. The Online Collaborative Whiteboard Platform to Bring Teams Together, Anytime, Anywhere. 2021. Available online: https: / / miro.com/ (accessed on 29 July 2021).

73. Berrigan, T. It's Official: NASA Is Making Cryosleep a Reality. Online. 2018. Available online: https://www.buzzworthy.com/ nasa-makes-cryosleep-a-reality / (accessed on 29 July 2021).

74. Thomas, J.A.P.K. The Social Environment of Public Transport. Ph.D. Thesis, Victoria University of Wellington, School of Psychology, Wellington, New Zealand, 2009.

75. Schuß, M.; Wintersberger, P.; Riener, A. Let's Share a Ride into the Future-A Qualitative Study Comparing Hypothetical Implementation Scenarios of Automated Vehicles. In Proceedings of the $2021 \mathrm{CHI}$ Conference on Human Factors in Computing Systems, Yokohama, Japan, 8-13 May 2021; Association for Computing Machinery: New York, NY, USA, 2021; pp. 1-11. [CrossRef]

76. Association, W.M. World Medical Association Declaration of Helsinki: Ethical principles for medical research involving human subjects. JAMA 2013, 310, 2191-2194. 